\title{
Global Role of Crop Genomics in the Face of Climate Change
}

\author{
Mohammad Pourkheirandish ${ }^{\dagger}$, Agnieszka A. Golicz ${ }^{\dagger}$, Prem L. Bhalla and Mohan B. Singh* \\ Plant Molecular Biology and Biotechnology Laboratory, Faculty of Veterinary and Agricultural Sciences, University of \\ Melbourne, Parkville, VIC, Australia
}

\section{OPEN ACCESS}

Edited by:

Nicola Colonna,

Italian National Agency for New

Technologies, Energy and

Sustainable Economic Development

(ENEA), Italy

Reviewed by:

Harsh Raman,

New South Wales Department of

Primary Industries, Australia

Ki-Hong Jung,

Kyung Hee University, South Korea

${ }^{*}$ Correspondence:

Mohan B. Singh

mohan@unimelb.edu.au

${ }^{t}$ These authors share first authorship

Specialty section:

This article was submitted to

Plant Biotechnology,

a section of the journal

Frontiers in Plant Science

Received: 24 December 2019

Accepted: 05 June 2020

Published: 16 July 2020

Citation:

Pourkheirandish M, Golicz AA,

Bhalla PL and Singh MB (2020)

Global Role of Crop Genomics in the

Face of Climate Change.

Front. Plant Sci. 11:922.

doi: 10.3389/fp/s.2020.00922
The development of climate change resilient crops is necessary if we are to meet the challenge of feeding the growing world's population. We must be able to increase food production despite the projected decrease in arable land and unpredictable environmental conditions. This review summarizes the technological and conceptual advances that have the potential to transform plant breeding, help overcome the challenges of climate change, and initiate the next plant breeding revolution. Recent developments in genomics in combination with high-throughput and precision phenotyping facilitate the identification of genes controlling critical agronomic traits. The discovery of these genes can now be paired with genome editing techniques to rapidly develop climate change resilient crops, including plants with better biotic and abiotic stress tolerance and enhanced nutritional value. Utilizing the genetic potential of crop wild relatives (CWRs) enables the domestication of new species and the generation of synthetic polyploids. The high-quality crop plant genome assemblies and annotations provide new, exciting research targets, including long non-coding RNAs (IncRNAs) and cis-regulatory regions. Metagenomic studies give insights into plant-microbiome interactions and guide selection of optimal soils for plant cultivation. Together, all these advances will allow breeders to produce improved, resilient crops in relatively short timeframes meeting the demands of the growing population and changing climate.

Keywords: domestication, genomics, climate change, crops, transcriptomics, abiotic stress

\section{INTRODUCTION}

The world will require a dramatic increase in food production in the next 30 years. Global food security is one of the key challenges of this century with the current human population of 7.7 billion expected to reach 8.6 billion in 2030 and 10 billion by 2050 (Tomlinson, 2013). The increase in population has led to an increase in urbanization, which is directly and indirectly, reducing our access to suitable land for agriculture (Satterthwaite et al., 2010). Simultaneously, the effects of climate change, including but not limited to increased temperature, changing patterns of rainfall, and increased levels of $\mathrm{CO}_{2}$ and ozone, impose further pressure on agriculture via drought and salinity that limit agricultural land and water use (Godfray et al., 2010).

Population growth is not the only reason we will need to increase food production. Significant income growth in rapidly developing economies gave rise to an emerging middle class, accelerating the dietary transition toward higher consumption of meat, eggs, and dairy products and boosting the need to grow more grain to feed more cattle, pigs, and poultry (Tilman and Clark, 2014). Agriculture in 2050 will need to produce almost $60-100 \%$ more food and feed than it is doing now (Tilman et al., 2011). This goal must be achieved despite the increase in global 
temperatures associated with climate change and growing scarcity of water and land, which are predicted to have significant impacts on the yield of all major crops.

In the last few centuries, plant breeders successfully used crossing and selection to improve the agronomic character of cultivated crops, such as wheat, maize, rice, barley, and others, resulting in dramatic increases in food production. However, agriculture has shifted to monoculture, resulting in the significant reduction of genetic diversity with today's global agricultural food depending on a few key plant species (Khoury et al., 2014).

The genetic gains achieved by conventional crop breeding and advanced agronomic practices have led to more than a double increase in crop yields between 1960 and 2015. The development of dwarf varieties of rice and wheat coupled with greater use of synthetic fertilizers and irrigation led to the first green revolution. However, the yield increases due to the green revolution are declining and/or beginning to plateau for the major food crops (Grassini et al., 2013). After years of improvement, we are getting close to the final capacity of these few crops on yield and their tolerance to biotic and abiotic stresses. The current trend of annual yield increases for major crops of between 0.9 and $1.6 \%$ is insufficient to meet requirements in the near future (Ray et al., 2013). It has been estimated that about $2.4 \%$ annual yield gain is required to meet the global food demand (Ray et al., 2013). Thus, development of high-yielding climate change resilient crops with enhanced tolerance to water deficit, temperature, and biotic stresses is critical for increasing productivity to keep pace with the increasing human population.

The challenge of feeding the increasing human population under climate change conditions is unlikely to be met by conventional breeding technologies alone. Plant breeding must adopt new, multidisciplinary approaches to enhance the rate of genetic gain (Varshney et al., 2018). Fortunately, the science underpinning plant breeding is being revolutionized by the recent conceptual and technological innovations including the development of rapid, cheap sequencing technologies and the rise of genomics allowing for the detailed analysis of plant genomes and dissection of the genetic basis of agronomic traits. Genomics is now at the core of crop improvement, including the identification of genetic variation underlying differences in phenotypes, identification of additional sources of variation and novel traits, and characterization of molecular pathways involved in biotic and abiotic stress tolerance.

Recently the development of genome editing technologies, especially CRISPR/Cas9, opened new routes of fast and precise genome modification promising rapid translation of knowledge from the lab to the field. Genome editing allows introduction of insertions/deletions or an entirely new sequence at a desired location in the target genome (Scheben et al., 2017). Known genes controlling important traits can be selectively modified using genome editing, allowing for manipulation of phenotypes. In recent years, several genome edited crop plants entered final stages of commercialization in the United States of America including drought and salt tolerant soybean, Camelina with increased oil content, and waxy corn (Waltz, 2018).

Considering the urgent need for crop plant improvement and the new, exciting technological and conceptual developments, this review outlines the potential of genomic approaches (Table 1) for the development of climate change resilient crops.

\section{USING GENOMICS TO IMPROVE CROP PLANT DIVERSITY AND RESILIENCE}

\section{Accessing Genetic Diversity of CWRs}

Wild plants have survived under a changing climate for millions of years, during which they have been subjected to selective pressure by biotic and abiotic factors. This natural selection has led to the accumulation of genes allowing plants to resist, tolerate, or avoid extreme temperatures, draught, or flooding, as well as pests and diseases. However, during subsequent domestication, many of those, now important, traits and associated genetic material were lost, transforming some of the plants into our current remarkably productive crops with limited genetic diversity (Figure 1). The remainder of the genetic resources was left behind and mostly treated as a weed. Insights gained from the genome sequencing projects of different crops

TABLE 1 | Summary of different approaches, which can be used to improve crop diversity and resilience.

Approach

Using genomics to improve crop plant diversity and resilience

Accessing genetic diversity of crop wild relatives (CWRs)

De novo crop domestication

Engineering polyploidy

Harnessing plant-microbe interactions

The challenge of climate change and plant diseases

Genome editing for nutritionally enhanced crops

Accessing new breeding targets using genomic technologies

Third-generation sequencing

Accurate gene prediction and functional annotation

Analysis of the non-coding part of genome

Pangenome as a reference sequence

Pairing genomics with other emerging technologies

Machine learning and crop plant genomics

Speed Breeding

High-throughput phenotyping

\section{Desired outcome}

Diversification of the existing breeding resources

Domestication of completely new crops using wild species

Controlled genome duplication or bridging the genomes of two related species

Optimal choice of suitable crops for the specific soil type and geographic location Prediction of pathogen evolution and prevalence and deployment of suitable protective measures ahead of time

Editing of target genes to improve crop nutritional value

Use of long sequencing reads for higher quality reference genome construction Precise candidate gene identification

Identification of new functional genomic sequences and breeding targets Inclusion of species-wide genomic variation in the analysis

Use of artificial intelligence for crop genotype and phenotype prediction

Shortening the breeding cycle

Increased resolution, accuracy and speed of plant phenotyping 


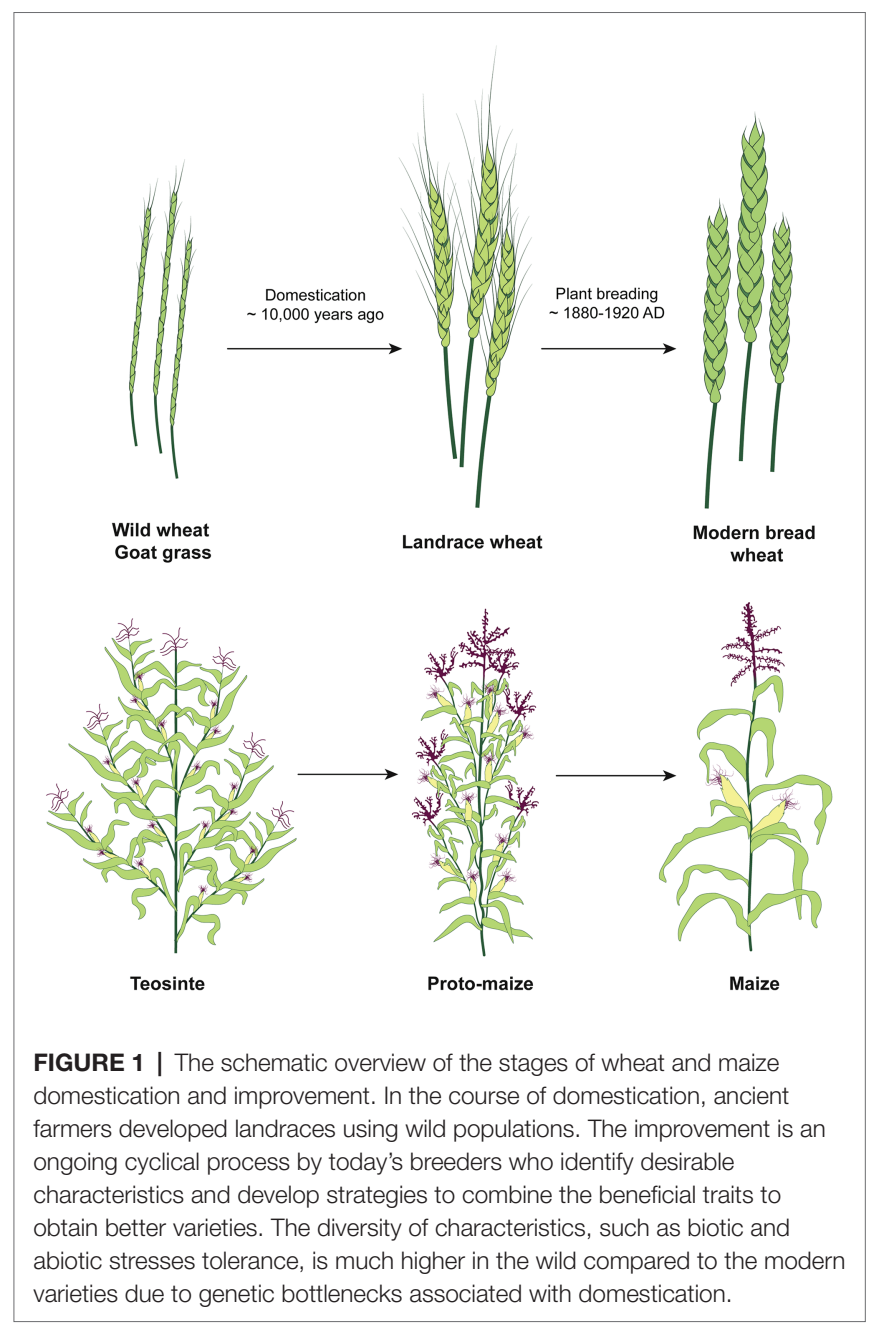

(Zhou et al., 2015b; Mascher et al., 2017; Appels et al., 2018; Springer et al., 2018; Zhao et al., 2018b) demonstrated the narrow germplasm of our modern crops and emphasized their vulnerabilities to climate change. However, all modern crop plants were domesticated from crop wild relatives (CWRs), which are still found in the wild, and provide a rich pool of genetic material, which is often excluded from the existing breeding programs (Brozynska et al., 2016).

Elite cultivated crops, such as wheat, maize, rice, and barley, are often dependant on farmer supplied resources, including water via irrigation, nutrition via fertilizers, and resistance to biotic stresses through the use of pesticides. This has led to the elite varieties becoming less resilient compared to their wild counterparts. In addition, strong artificial selection for a handful of crucial traits resulted in reduced diversity and restriction of the gene pool available within breeding programs. CWRs constitute an additional source of genetic diversity, which can be utilized during crop improvement programs, with as much as $30 \%$ of the increases in crop yields during the late 20th century being attributed to the use of CWRs in plant breeding programmes (Pimentel et al., 1997; Brozynska et al., 2016).

Over 1,500 CWRs of food crops have been identified as a potential source of genetic diversity for 173 globally important

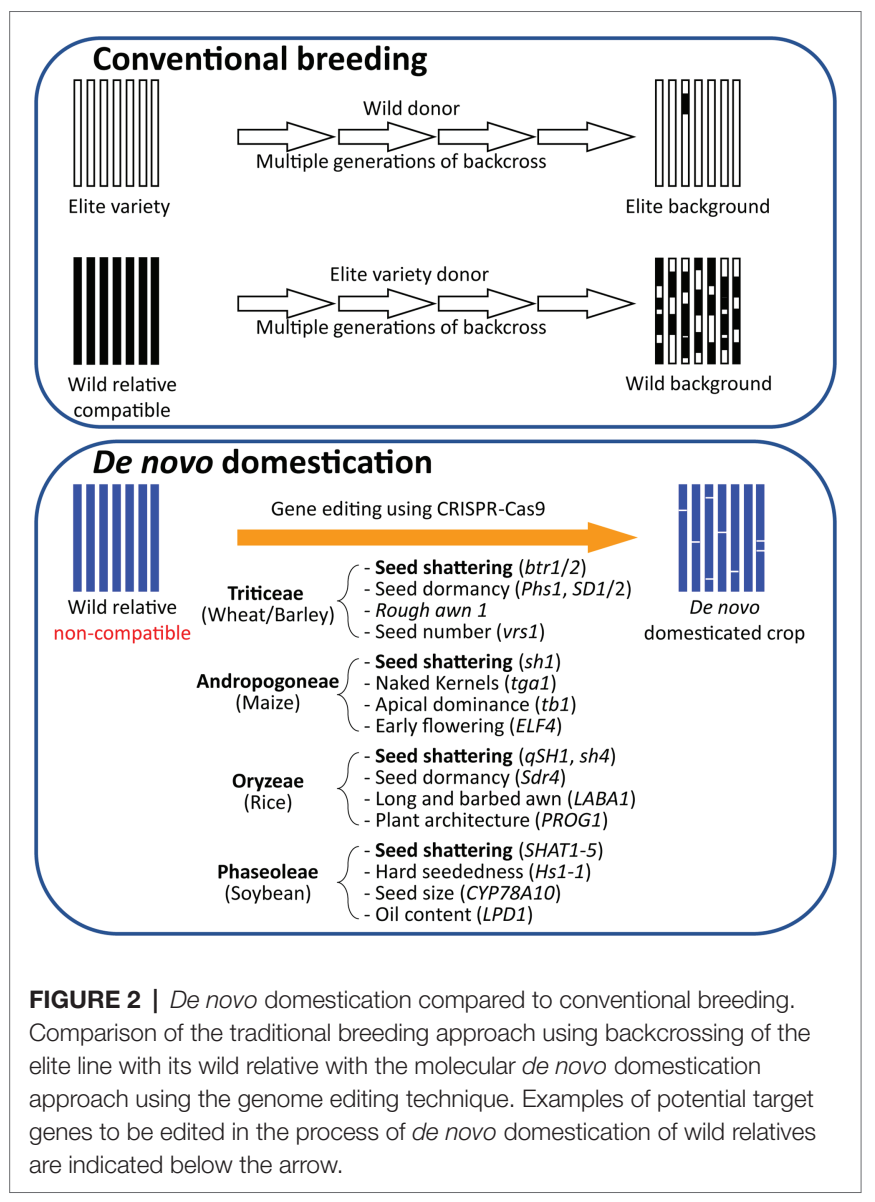

crops (Vincent et al., 2013). Advances in sequencing technologies facilitated construction of CRW reference genomes, which in turn can be used in comparative genomics analyses, allowing for the identification of novel genes controlling key traits (Brozynska et al., 2016).

Traditionally, the new genetic material was transferred from CWRs to crop plants by introgression of new genes into elite cultivar background (Figure 2; Dempewolf et al., 2017). Genomic resources have been widely used to speed up the process via marker assisted selection, including transfer of disease resistance genes in grape vine, apple, and banana (Migicovsky and Myles, 2017). Despite its obvious success, especially in transfer of major genes, the method is time consuming and restricted to sexually compatible species. For example, Hordeum vulgare (cultivated barley) has been extensively crossed with cross-compatible Hordeum spontaneum (wild progenitor), and there has been limited success crossing cultivated barley with Hordeum bulbosum, where chromosome segment from $H$. bulbosum can be transferred to the chromosomes of cultivated barley (Westerbergh et al., 2018). There are however 32 species in the genus Hordeum, including diploid, tetraploid, and hexaploid varieties (Bothmer et al., 1995), and the vast majority of Hordeum species cannot be used due to crossing barriers. However, once the candidate genes have been identified, transgenics and genome editing technologies can be used to transfer the desirable genetic material between species regardless of natural crossing barriers. To aid improvement, 
rich CWR genomic resources for many key crop species have been developed including soybean, rice, and maize.

Glycine soja - a wild relative of cultivated soybean (Glycine max) - has been shown to have a much more diverse gene pool compared to G. max, due to artificial selection during domestication and further loss as a result of modern breeding practices (Hyten et al., 2006; Kofsky et al., 2018). Wild and cultivated soybean differ in a number of agriculturally important traits, including pod shattering (Dong et al., 2014), determinate growth habit (Tian et al., 2010), and seed size (Zhou et al., 2015a; Kofsky et al., 2018). Additionally, it was shown that half of the annotated resistance-related sequences in G. soja were absent in both the landraces and cultivars (Zhou et al., 2015b). Despite the phenotypic differences, G. soja and G. max are cross-compatible, facilitating the transfer of desirable traits.

In maize (Zea mays), lowland teosinte ( $Z$. mays ssp. parviglumis), highland teosinte ( $Z$. mays ssp. mexicana), and the genus Tripsacum comprising nine species of warm-season, perennial grasses have been characterized as donors of important traits, which could be used for improvement (Mammadov et al., 2018). Genome-wide studies demonstrated that over $10 \%$ of the maize genome shows evidence of introgression from the mexicana genome, suggesting its contribution to adaptation and improvement (Hufford et al., 2013; Yang et al., 2017).

Rice (Oryza sativa L.) belongs to the genus Oryza, encompassing over 20 species, two of which are cultivated (O. sativa L. and Oryza glaberrima S.). The species are subdivided into several groups, and not all are cross-compatible. In recent analyses, Oryza rufipogon, a wild species believed to be the immediate progenitor of $O$. sativa, showed higher sequence diversity and harbored sequence and genes completely missing from the population of cultivated rice (Huang et al., 2012; Xu et al., 2012; Zhao et al., 2018b), highlighting the potential of its use for modern rice improvement.

In Brassica, a comparison of a CWR Brassica macrocarpa, with nine cultivated lines of Brassica oleracea showed that the former harbored unique disease resistance genes most likely lost during the domestication and improvement of elite $B$. oleracea germplasm (Golicz et al., 2016b).

The increasing abundance of genomic resources for CWRs will significantly aid future breeding efforts, helping identify the optimal crosses and genome editing targets.

\section{De novo Crop Domestication}

Another strategy for utilization of the wild plant resources is new crop (de novo) domestication. The domestication syndrome refers to a unique collection of phenotypic traits associated with the genetic change of an organism from a wild progenitor to a domesticated one. Most of the changes linked to the domestication syndrome, such as grain dispersal in wheat, barley, and rice; apical dominance in maize; fruit size in tomato; and grain quality in wheat, result from modification of a single or few genes (Frary et al., 2000; Clark et al., 2004; Konishi et al., 2006; Uauy et al., 2006; Dubcovsky and Dvorak, 2007; Pourkheirandish et al., 2015, 2018). Also, most of them are due to a loss of function mutation in the causal gene (Komatsuda et al., 2007; Ramsay et al., 2011; Ishimaru et al., 2013; Pourkheirandish et al., 2015).
For example, wheat, barley, rice, maize, and sorghum were selected for inflorescence that retained the grains, which made it easy to harvest. This characteristic results from the loss of function mutations in the genes controlling shattering (Konishi et al., 2006; Lin et al., 2012; Pourkheirandish et al., 2015). Similarly, a domestication associated NAC gene controlling pod shattering resistance has been identified in soybean (Dong et al., 2014). Advances in genomics provided the necessary platform to facilitate gene discovery and identification such as detection of genes associated with non-brittle rachis in pasta wheat and seed filling in maize using whole-genome sequencing (Sosso et al., 2015; Avni et al., 2017); smooth awn in barley using genotyping by sequencing (Milner et al., 2019); seed quality in soybean; and cutin responsible for water retention in barley using RNA sequencing (Li et al., 2012, 2017a; Gao et al., 2018).

The syntenic and orthologous gene relationships among plant genomes are well demonstrated (Devos, 2005; Tang et al., 2008). Synteny allows identification of homologous genes and has been used to identify genes with similar functions in related species (Pourkheirandish et al., 2007; Chen et al., 2009; Sakuma et al., 2010; Ning et al., 2013). For example, grain retention in both wheat and barley results from a mutation in homologous genes brittle rachis 1 (Pourkheirandish et al., 2018). The brittle rachis 1 homologues appear to have a similar role in grain dispersal in wild progenitors of wheat and barley. A loss of function mutation in this gene results in spike stiffness in the domesticated lines. As the same gene controls brittleness in both wheat and barley, brittle rachis 1 most likely evolved before the divergence of Triticum (wheat genus) and Hordeum (barley genus) over 5 Mya (Middleton et al., 2014). This suggests that the other non-domesticated species within Hordeum and Triticum that are not cross fertile with cultivated wheat and barley probably carry the brittle rachis 1, which controls their mode of grain dispersal. Recently a study involving crop plant species from multiple families used genome-wide association study (GWAS) to identify a domestication-related gene controlling seed dormancy in soybean and then showed that orthologs of this gene in rice and tomato also display evidence of selection during domestication. Analysis of transgenic plants confirmed the conservation of function in soybean, rice, and Arabidopsis, highlighting the power of comparative genomics in new domestication target gene identification (Wang et al., 2018a).

A pre-existing knowledge of target gene makes further crop domestication speedy and feasible. Domestication of a new crop species allows access to a novel gene pool with the potential for generating new crops, which are productive, resilient, and nutritious. Recent successes in wild tomato domestication by editing loci important for yield and productivity provide a proof of concept (Li et al., 2018; Zsögön et al., 2018). For example, targeting of brittle rachis 1 gene in any wild species of Hordeum or Triticum using gene editing would disrupt its function and result in a significant step toward domestication of a new species. It is important to note that the ease of genome editing and therefore its use for crop de novo domestication and other applications is related to plant ploidy. Gene knockout efficiency is lower in polyploids compared to diploids, as multiple alleles must be edited simultaneously to achieve a similar effect (Zhang et al., 2019b). 


\section{Engineering Polyploidy}

Polyploid plants possess three or more sets of homologous chromosomes stemming either from the duplication of a single genome (autopolyploidy) or hybridization followed by doubling of two diverged genomes (allopolyploidy; Comai, 2005). Many of the agriculturally important crop plants and staple food species are natural polyploids, including: bread wheat (allo-hexaploid; $6 \times=42$ ), pasta wheat (allo-tetraploid; $4 \times=28$ ), strawberry (allo-octaploid; $8 \times=56$ ), potato (auto-tetraploid; $4 \times=48$ ), and banana (auto-triploid; $3 \times=33$ ). Recent modeling work linked the occurrence of polyploidy to domestication (Salman-Minkov et al., 2016). Higher genome copy number masks deleterious mutations, increases the adaptive potential, and provides the opportunity for genes to gain new function. Thus, polyploidy is considered a major driver of evolution (Sattler et al., 2016). Induced polyploidy has also been used by breeders to develop new crops and flowers, such as triploid watermelon (seedless), hexaploid Triticale (a hybrid of wheat and rye), triploid tulips, roses, and many more ornamental flowers (Sattler et al., 2016). Polyploid plants tend to display hybrid vigor and improved abiotic stress tolerance (Chen, 2010; Tamayo-Ordóñez et al., 2016), with different manifestations of traits observed depending on the level of ploidy. For example, a study in Arabidopsis, which performed a rigorous comparison of plants with different somatic ploidy levels $(2 \times, 4 \times, 6 \times$, and $8 \times)$ observed significant differences in phenotypes (Corneillie et al., 2019).

The engineering of polyploid plants has been proposed as one of the routes for the generation of improved crop varieties (Katche et al., 2019). However, a better understanding of the causes and effects of polyploidy is a necessary prerequisite. Two major routes of polyploid plant formation are via unreduced gametes or somatic doubling (Ramsey and Schemske, 1998; Tamayo-Ordóñez et al., 2016). In laboratory conditions, polyploidy can be induced by application of antimicrotubule drugs such as colchicine. The viability of polyploid plants depends on stabilization of mitotic and meiotic divisions (Comai, 2005). Understanding of the molecular mechanisms behind cell cycle control, homologous chromosome pairing, and meiotic crossover formation is therefore paramount. Molecular mechanisms controlling cell cycle progression are deeply conserved and rely on cyclins (CYCs) and cyclin dependent kinases (CKDs). Previous studies in Arabidopsis thaliana identified seven classes of CDKs, named CDKA through CDKF, but CDKA and CDKB were identified as major drivers of cell cycle in plants (Menges et al., 2005; Tank and Thaker, 2011; Tamayo-Ordóñez et al., 2016). An extensive literature search compiled a list of over a 100 meiosis-related genes in Arabidopsis (Gaebelein et al., 2019). Comparative genomics approaches can be used to find orthologs of those genes in other species and perform further characterization. For example, a recent study of synthetic allohexaploid Brassica hybrids $(2 n=6 \times=$ AABBCC $)$ identified genomic regions associated with fertility, which harbored orthologs of $A$. thaliana genes involved in meiosis (Gaebelein et al., 2019).

In addition, plant genomes are known to undergo extensive structural rearrangements and methylation changes upon polyploidization. A study of resynthesized Brassica napus lines demonstrated extensive restructuring of the merged genomes in the early generations following hybridization (Szadkowski et al., 2010). Many hybrids and recent allopolyploids display genome dominance, resulting in sub-genome biases in gene content and expression (Bird et al., 2018). Genomics can be used to track post-hybridization structural re-arrangements and the establishment of sub-genome dominance to better understand plant genome evolution post-hybridization (Edger et al., 2017). It can also help predict the optimal combination of different wild species to construct new synthetic crops that can diversify our agriculture and bring resilience to climate change.

As an example, bread wheat (Triticum aestivum), a major crop accounting for $20 \%$ of world daily food consumption, is an allohexaploid plant originated via multiple hybridizations. The most accepted hypothesis of its origin is demonstrated in Figure 3 (Haider, 2013). Because the bread wheat carries genes of three different genomes $(A, B$, and $D)$, it is robust and has been able to adapt to different climatic zones. Today, bread wheat (AABBDD), which originated from fertile crescent $\left(30-35^{\circ} \mathrm{N}\right)$, can grow from Sweden $\left(65^{\circ} \mathrm{N}\right)$ to Argentina or New Zealand $\left(45^{\circ} \mathrm{S}\right)$, a cultivation zone much broader than that pasta wheat (AABB; Feuillet et al., 2008). Another example of a widely known polyploid plant is the octoploid strawberry (Edger et al., 2019). The modern strawberry arose from a series of hybridization events between diploid, tetraploid, and hexaploid species spanning Eurasia and North America (Figure 4).

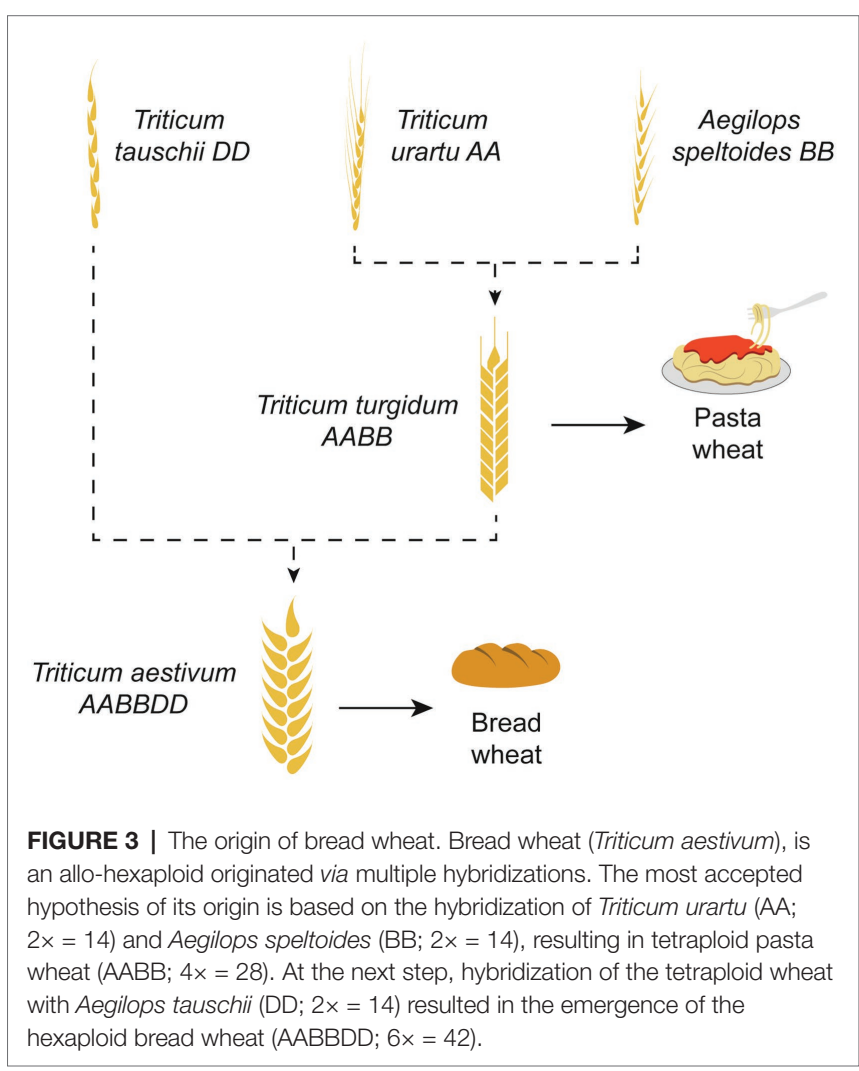




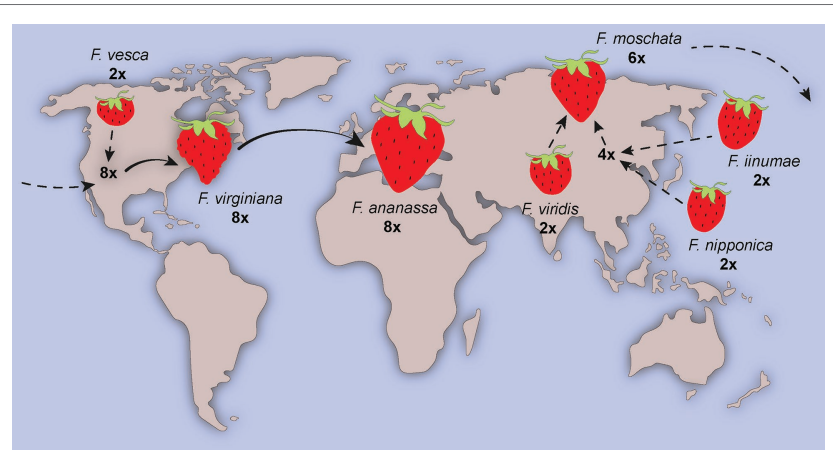

FIGURE 4 | The origin of strawberry. Strawberry is an allo-octoploid originated from multiple hybridization events in Eurasia and America. Modern variety Fragaria $\times$ ananassa resulted from cross between two octoploid genotypes Fragaria virginiana and Fragaria chiloensis. Figure adapted from Bertioli (2019).

\section{Harnessing Plant-Microbe Interactions to Boost Agricultural Output}

Microbes which live within (endosphere) and surrounding plant roots in the soil (rhizosphere) have a significant impact on the host, including health and fitness, productivity, and responses to climate change (Wei et al., 2019). Plants and microbes interact via signaling molecules originating from both organisms (Leach et al., 2017; Chagas et al., 2018). Some bacterial communities have been shown to manipulate the plant potential to use soil resources, promote plant biotic and abiotic stress tolerance, and stimulate growth and nutrient uptake (Mendes et al., 2011; Berendsen et al., 2012; Fellbaum et al., 2012; Fitzpatrick et al., 2018; Paredes et al., 2018). At the other end of the spectrum, pathogenic microbes also exist, which negatively affect plant health (Figure 5; Pusztahelyi et al., 2015; Chagas et al., 2018).

Soil microorganisms are in constant competition to accumulate around the root and access the plant secreted carbohydrates (Venturi and Keel, 2016). Plants and microbes evolved together, resulting in beneficial microbes being attracted to a specific root exudate profile and forming a community of microbes in the rhizosphere (Garbeva et al., 2008). Plant species can therefore shape the composition of their rhizosphere's microbiome. Crops grown in the soils with microbial profiles similar to their native environment are expected to have a better chance of forming beneficial plant-microbiome interactions (PérezJaramillo et al., 2018), promoting tolerance to biotic and abiotic stress. The advances in genomic technologies resulted in the sequencing of numerous soil microorganisms and improvement of our understanding of the soil microbial communities (Jansson and Hofmockel, 2018). For example, the availability of genomic sequences for nitrogen-fixing and phosphate-solubilizing bacteria expanded significantly (Zekic et al., 2017; Basenko et al., 2018; Jeong et al., 2018; Ormeño-Orrillo et al., 2018). Combined analysis of microbiome genomic and metabolomic data provides an accurate tool necessary to understand plant-microbe interactions and predict the most favorable crop plant-soil microbiome combinations, allowing for mapping of suitable crops to specific locations.

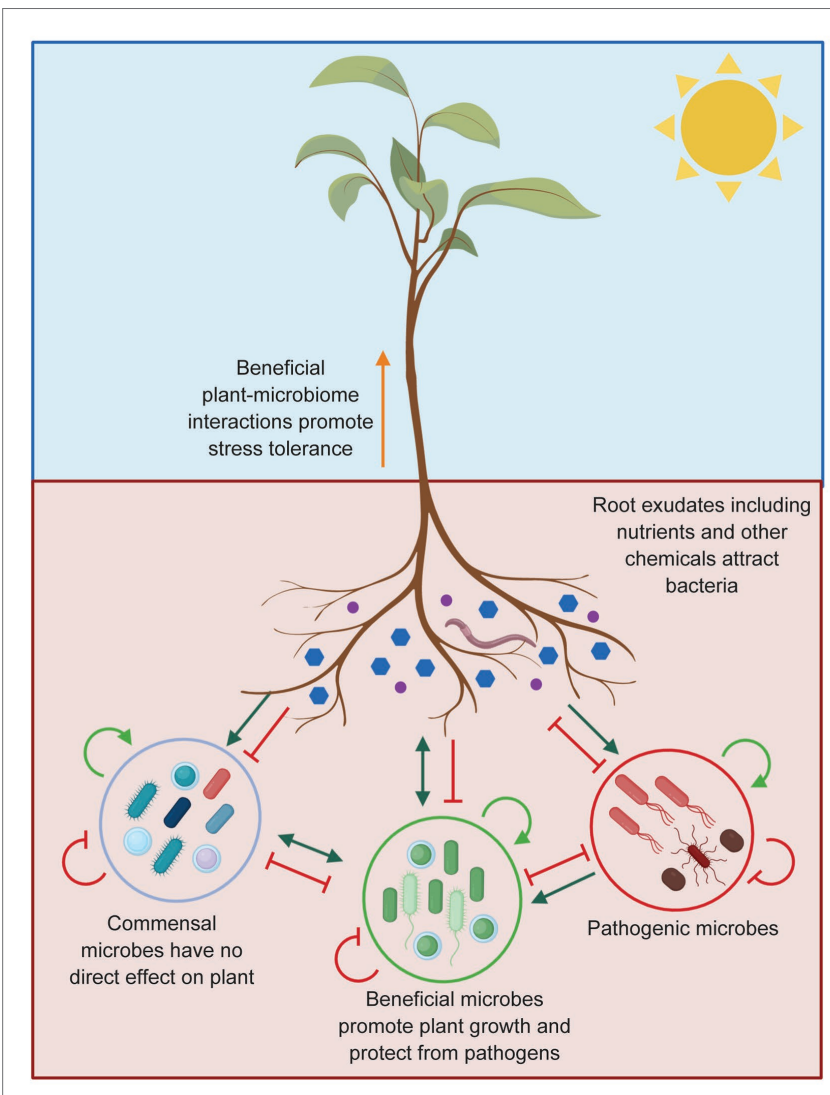

FIGURE 5 | Plant-microbe interactions in the rhizosphere. Plants can influence the composition of microbiome surrounding plant roots through exudation of compounds that stimulate (green arrows) or inhibit (red blocked arrows) microbes. A wide range of pathogens living in the soil can also affect plant health. Being able to attract the beneficial microbes will limit the success of the pathogenic microbes due to resource competition or by enhancing the plant immune system. The commensal microbes do not affect the plant or the pathogen directly. Microbiome-plant interactions are presented as described by Berendsen et al. (2012).

\section{The Challenge of Climate Change and Plant Diseases}

Crop plant pathogens are considered a major threat to modern agriculture (Oerke and Dehne, 2004; Savary et al., 2012; Nelson et al., 2018). The ongoing battle between plants and pathogens resulted in their co-evolution and shaped the genetic diversity of both (Jones and Dangl, 2006; Tiffin and Moeller, 2006; Dodds and Rathjen, 2010; Hartmann et al., 2017). Diseases generally result from a specific interaction between host and pathogen (Veresoglou and Rillig, 2014; Pôlme et al., 2018). For example, the wheat leaf rust pathogen Puccinia triticina, one of the most common diseases of wheat globally, does not affect rice, maize, or any other crop. World-wide over-cultivation of a few crops (wheat, maize, rice, soybean, and barley) with low genetic diversity has led to the increased pathogen inoculum and accelerated pathogen evolution, promoting its spread globally (Savary et al., 2019).

Climate change affects the epidemiology of pathogens at specific locations and the geographic distribution of plant 
diseases (Barford, 2013; Chakraborty, 2013). Increasing the crop plant diversity by cultivation of orphan crops and the domestication of new crops will result in reduced selective pressure on pathogen populations; thus, the life of genetic resistance is expected to be longer (Cook, 2006; Hajjar et al., 2008; Storkey et al., 2019). The life extension of genetic resistance could be an effective and ecologically sustainable way to control diseases. Climate change affects not only the crop but also the pathogen survival and reproduction. One of the expected impacts of climate change on plant disease is the migration of pathogens to latitudes beyond their historical range, examples of which have already been documented (Barford, 2013; Chakraborty, 2013). An increase in temperature would result in pathogen movement and spread of disease further from north in the northern hemisphere and south in the southern hemisphere to geographical locations in which they previously have not been able to reproduce effectively nor infect the plant. Recent genomic advances have resulted in the prediction and isolation of several resistance genes from crops and the identification of the corresponding genes from the pathogen (Fu et al., 2009; Mago et al., 2015; Moore et al., 2015; Sperschneider et al., 2015; Krattinger et al., 2016; Wan et al., 2019). These advances have provided a snapshot of resistance mechanisms that crops have developed during the long co-evolutionary history. The discovery of the genes underlying resistance has led to an improved understanding of their molecular function and established an entry point for studies of the defense pathways.

In addition, genome sequencing provides a rapid method of pathogen identification (Boykin et al., 2019), outbreak progression, and tracking of its spread to new locations. In fact, the development of third-generation sequencing technologies, especially Oxford Nanopore, resulted in the introduction of small, affordable, mobile sequencing instruments perfectly suited for in-field diagnostic system. Oxford Nanopore MinION technology has already been used for real-time diagnostics of human pathogens including Ebola (Quick et al., 2016) and Zika viruses (Faria et al., 2016) with protocols for identification of plant pathogens and pests under active development. For example, a recent proof-of-concept study has shown that using portable sequencing technology diagnostic test, it is possible to deliver test results within $48 \mathrm{~h}$ and, thus, greatly reduce the risk of community crop failure (Boykin et al., 2019).

\section{Genome Editing for Nutritionally Enhanced Crop Production}

Augmentation of crop nutritional value plays a central role in ensuring global food security. Breeding of crops for enhanced nutrient content has been a long standing goal of plant research (DellaPenna, 1999; Welch and Graham, 2002). Plants are a key source of macro- and micro-nutrients, but many of the staple foods, including cassava, wheat, rice, and maize are poor source of some macro-nutrients and many essential micro-nutrients (DellaPenna, 1999). However, nutrient profile can be altered by manipulation of biochemical pathways involved in macro- and micro-nutrient biosynthesis. Advances in genome sequencing and annotation provided the necessary resource to identify the candidate genes involved in plant metabolism. As a result, genome editing technologies could be used to modify nutritional profiles of crops, for example producing soybeans with high oleic acid and low linoleic acid content (Haun et al., 2014; Demorest et al., 2016) and reducing antinutritional phytic acid content in maize (Liang et al., 2014). Nutritional enhancement of crops can also be achieved using transgenic technologies (Hefferon, 2015). In addition, genome editing facilitated de novo domestication of new nutrient rich crops could lead to a more diversified and healthier diet.

\section{ACCESSING NEW BREEDING TARGETS USING GENOMIC TECHNOLOGIES}

\section{Third-Generation Sequencing for Improved Reference Genomes}

The beginning of the twenty-first century saw rapid development of new sequencing methods. Second-generation sequencing technologies, including Illumina, allowed assembly of over 200 plant genomes (Chen et al., 2018) with much more ambitious plans of generating 10,000 draft genome assemblies by 2025 (Cheng et al., 2018). The main challenge posed by second-generation sequencing technologies was short-read length, making them unable to bridge over long stretches of repetitive sequences, resulting in fragmented assemblies. However, the introduction of third-generation sequencing and long reads produced by PacBio and Oxford Nanopore now allows for chromosomal level assemblies of plant genomes (Belser et al., 2018). The long-read sequencing technologies are often combined with optical mapping and conformation capture, achieving draft genomes of unprecedented contiguity (Belser et al., 2018; Shi et al., 2019). Importantly, the sequencing strategy used and the resulting contiguity and completeness of the assembly have been shown to impact downstream evolutionary and functional analyses. For example, comparative analysis of two Brassica rapa assemblies, one built using Illumina sequencing data and the other one using a PacBio, optical mapping (BioNano) and conformation capture (Hi-C) revealed that the latter harbored $\sim 3,000$ assembly specific genes as well as over 500 previously unidentified transposable element (TE) families (Zhang et al., 2018). The availability of high-quality, chromosome scale genome assemblies substantially improves the accuracy of the downstream genomic analysis, including gene and regulatory region annotation, GWAS, gene expression quantification, and homologue detection.

\section{Accurate Gene Prediction and Functional Annotation for Precise Candidate Gene Identification}

The explosion of plant genome sequencing was accompanied by extensive annotation efforts aiming to generate a comprehensive catalog of gene models for a given species. Gene model is defined as a region of the genome, which is believed to be transcribed into protein-coding messenger RNA (mRNA) or one of the classes of non-coding RNAs (ncRNA; Schnable, 2019). Gene models are often built using a combination of $a b$ 
initio gene prediction and homology-based methods that take advantage of sequence similarity to known transcripts or proteins (Campbell et al., 2014; Klasberg et al., 2016). Early on gene expression evidence was mostly derived from expressed sequence tags (ESTs) and extended by full-length sequencing via cloning followed by Sanger sequencing. Later, the information was supplemented by RNASeq data from diverse tissues, and it was shown that gene models and isoforms with highly tissue-specific expression were underrepresented in exiting annotations (Cheng et al., 2017; Golicz et al., 2018b; Van Bel et al., 2019). Currently, addition of long reads generated by PacBio or Oxford Nanopore sequencing technologies allows for recovery of full-length transcripts, providing new insights into the extent of alternative splicing and transcriptome diversity (Cook et al., 2019). Annotation of loci harboring non-coding transcripts is also becoming routine, further improving our understanding of the complexity of plant transcriptomes (Van Bel et al., 2019).

Despite the availability of genome annotations, functional characterization of annotated genes, which allows for the direct connection between genome and phenome, poses a key challenge in molecular breeding pipelines (Scheben and Edwards, 2018). In the key experimental model plant species, A. thaliana, $>90 \%$ of genes have been annotated with putative functions and $~ 50 \%$ of genes have annotation supported by experimental evidence (Van Bel et al., 2019). However, for most of the crop plants, gene functional annotations rely on homology-based inference and are performed by transfer of annotation from most similar genes in model plants like Arabidopsis and rice, with very little direct experimental support. Annotation transfer is further complicated by plant evolutionary history, where successive rounds of polyploidy and subsequent diploidization lead to gene redundancy, differential loss, and neo- and sub-functionalization (Jiao and Paterson, 2014; Salman-Minkov et al., 2016). However, rapid progress in application of CRISPR/Cas9 genome editing will soon allow construction of genome-wide mutant libraries for key crops, significantly contributing to the functional annotation efforts. In fact, such libraries are already available for rice (Lu et al., 2017; Meng et al., 2017). Integrative genomics approaches have also been used to facilitate discovery of top candidates. For example, specialized databases integrating genotypic, phenotypic, and association data have been developed for rice (SNP-Seek), soybean (SoyBase), and wheat (T3; Grant et al., 2010; Blake et al., 2016; Mansueto et al., 2017). Beyond specialized database, tools like KnetMiner and MCRiceRepGP were developed aiming to rank candidate genes involved in biological processes of interest using multicriteria decision analysis (Hassani-Pak and Rawlings, 2017; Golicz et al., 2018b).

\section{Non-coding Part of Genome as a Reservoir of New Breeding Targets}

Only several percent of most large crop plant genomes encode protein-coding genes and the remainder is made up of non-coding sequences. For a long time, the non-coding stretches of DNA were considered to have little function; however, recent technological and conceptual developments revealed that plant genomes encode thousands of potentially functional ncRNAs as well as prevalence of distant regulatory elements including enhancers (Weber et al., 2016). The ncRNAs encompass several classes of transcripts, including not only the relatively well characterized ribosomal RNAs (rRNAs), transfer RNAs (tRNAs), small nucleolar RNAs (snoRNAs), and micro RNA (miRNAs) but also much more poorly understood long non-coding RNAs (lncRNAs). LncRNAs are transcripts over 200 base pairs in length without discernible protein coding protentional, identified from RNASeq data, and have been shown to be involved in a range of biological processes, including flowering time regulation, stress tolerance, and gamete formation (Golicz et al., 2018a). At least some of the lncRNAs are likely to be functional, as evidenced by mutant phenotypes of knock-outs of newly discovered lncRNAs (Huang et al., 2018). Interestingly, lncRNAs have a strong bias toward transcription in reproductive tissues (Zhang et al., 2014; Golicz et al., 2018b; Johnson et al., 2018), suggesting involvement in plant sexual reproduction, a critical process affecting flowering, fruit, and grain formation. Newly characterized lncRNA, which affect important traits, can become genome editing targets. For example, a rice lncRNA LDMAR was shown to be involved in control of photoperiod-sensitive male sterility (PSMS), a key trait which contributed to the development of hybrid rice (Ding et al., 2012).

Another promising category of non-coding DNA sequences are cis-regulatory elements (CREs, promoters and enhancers/ silencers), capable of recruiting transcription factors and promoting gene expression. Changes in CREs are considered one of the key evolutionary mechanisms underlying, for example, emergence of novel morphological forms (Stern and Orgogozo, 2008; Weber et al., 2016) and the divergence of cis-regulatory regions associated with domestication underscore their important roles in control of traits targeted by artificial selection (Lemmon et al., 2014; Wang et al., 2017). Several enhancers have been identified that modulate the expression of genes involved in the control of important traits, like anthocyanin content in maize and flowering time in Arabidopsis (Chua et al., 2003; Louwers et al., 2009; Adrian et al., 2010). SNPs corresponding to the different rapeseed ecotype groups were also identified in the promoter regions of FLOWERING LOCUS $\mathrm{T}$ and FLOWERING LOCUS C orthologs (two key genes controlling flowering time; Wu et al., 2019). An SNP corresponding to spatial expression of a homeobox transcription factor was selected for during the selection of non-shattering rice (Konishi et al., 2006). An insertion of TE in the CRE of teosinte branched 1 gene was discovered as the reason for apical dominance in maize also selected in the course of plant domestication (Studer et al., 2011). In the last few years, a significant progress has been made in identification of plant CREs with studies of the model plant species Arabidopsis as well as rice, maize, and cotton (Zhang et al., 2012; Pajoro et al., 2014; Zhu et al., 2015; Rodgers-Melnick et al., 2016; Oka et al., 2017; Wang et al., 2017; Bajic et al., 2018; Tannenbaum et al., 2018; Zhao et al., 2018a; Yan et al., 2019). The rapid developments are due to adoption of DNase-Seq and ATAC-Seq techniques in plant research, which measure DNA "openness" as a proxy for the accessibility of DNA to transcription factors, RNA polymerase, and other protein complexes involved in gene expression (Pajoro et al., 2014; Wang et al., 2016). Improved understanding of 
the function of the non-coding elements of the genome will provide a new, yet untapped pool of breeding targets.

\section{Beyond Single Reference Genomics - The Pan-Genome Approach}

Generation of the reference genomes and subsequent large-scale re-sequencing of hundreds to thousands of individuals per species revealed extensive genomic diversity, including large-scale presence/ absence variation (Golicz et al., 2016a; Varshney et al., 2017, 2019; Fuentes et al., 2019; Wu et al., 2019). As our knowledge of genomic variation increased, it become apparent that a single reference sequence is insufficient to represent the extent of genomic variation found within species, resulting in the introduction and adoption of the pangenome concept (Figure 6; Golicz et al., 2020). Pangenome represents the entirety of the genomic sequence and gene content found within a species rather than a single individual. First introduced in bacteria (Tettelin et al., 2005), it is highly relevant to plant research with more than $50 \%$ of genes in some species being variable (accessory), found in some individuals but not others (Golicz et al., 2020). Pangenomes have been constructed for key crop species, such as rice, soybean, bread wheat, and oilseed rape (Li et al., 2014; Golicz et al., 2016b; Contreras-Moreira et al., 2017; Gordon et al., 2017; Montenegro et al., 2017; Zhou et al., 2017; Hurgobin et al., 2018; Ou et al., 2018; Zhao et al., 2018b; Gao et al., 2019; Zhang et al., 2019a). Plant accessory genes have been shown to be over-represented in functions related to signaling and disease resistance as well as abiotic stress response (Golicz et al., 2016b; Montenegro et al., 2017; Hurgobin et al., 2018; Wang et al., 2018b), perhaps contributing to environmental adaptation and phenotypic plasticity and providing promising targets for crop improvement. Especially, since some of the accessory genes may be completely missing from the elite germplasm.

In addition, the pangenome offers a natural replacement for the current paradigm of using a single reference genome, as the choice of the reference affects downstream genomic analyses, including GWAS and gene expression quantification (Gage et al., 2019). Using pangenome as a reference improves read mapping and variant calling accuracy (Eggertsson et al., 2017; Garrison et al., 2018; Kim et al., 2019; Tian et al., 2019). The adoption

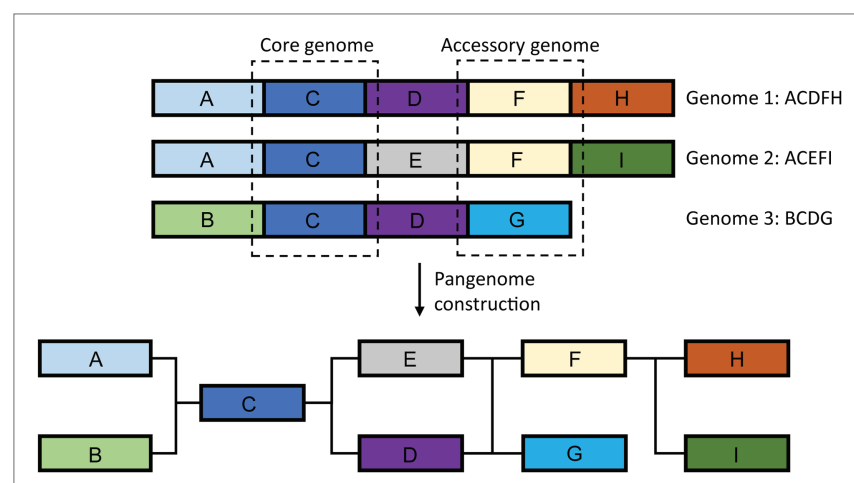

FIGURE 6 | Schematic representation of the plant pangenome. Pangenome represents the entire genomic sequence found in the species. of the pangenome reference will also allow the inclusion of variants beyond SNPs in GWAS. Several studies in both plants and humans showed that the inclusion of structural variants in association studies could help identify causal variants (Chiang et al., 2017; Fuentes et al., 2019). For example, the use of sequence presence/absence variation allowed the identification of missing quantitative trait locus (QTLs) associated with disease resistance in oilseed rape (Gabur et al., 2018).

\section{PAIRING GENOMICS WITH OTHER EMERGING TECHNOLOGIES TO MAXIMIZE THEIR POTENTIAL}

\section{Machine Learning and Crop Plant Genomics}

Almost all aspects of genomic analyses can now be supported by the development and implementation of machine learning algorithms. Machine learning algorithms find new patterns and "learn" the necessary predictive features from the data, rather than rely on pre-existing criteria. This property makes them suitable for analysis of complex, multilayer datasets, where expert knowledge is incomplete or inaccurate, and when the amount of data is too large to be handled manually (Yip et al., 2013). Several promising applications of machine learning to plant genomics exits. As discussed above, the functional non-coding portions of plant genomes remain largely poorly understood. In animal research, machine learning and deep learning based methods have been particularity successful in genomic feature annotation, including regulatory regions like promoters, enhancers, and transcription factor binding sites (Xu and Jackson, 2019). The use of machine learning improved the quality of feature annotation, helped uncover the underlying sequence characteristics of the regulatory regions, and even allowed prediction of variant impact (Zhou and Troyanskaya, 2015; Kelley et al., 2016). However, the limited availability of large-scale epigenetic modification and chromatin accessibility datasets may delay similar studies in crop plants. While the lack of suitable datasets may be hampering regulatory region annotation, hundreds of sequenced and assembled genomes are readily available for comparative analyses. Identification of conserved and unique elements is one of the primary aims of comparative genomics. To date, sequence comparisons are mostly based on local or whole-genome alignments and limited by sensitivity of alignment tools. However, machine learning algorithms are being developed, which are capable of computing probability of sequence conservation for any query of interest (Joly-Lopez et al., 2016; Li et al., 2017b), providing new, exciting avenues for plant comparative genomics. Finally, plant phenotyping has legged significantly behind genotyping, requiring considerable resources and specialized equipment (Scheben and Edwards, 2018). One proposed application of machine learning is the prediction of phenotype from genotype and complementation of the more traditional genomic prediction models (Ma et al., 2018). Taken together, machine learning methods have the potential to add significant value to the existing genomic resources and methodologies. 


\section{Speed Breeding to Accelerate the Development of New Crops}

Advances in molecular and genomic technologies resulted in isolation and characterization of many agronomically important genes, for example ones controlling seed shattering, dormancy, increasing seed number, and size (Doebley et al., 2006). Improved understanding of the molecular function of these genes makes the new crop domestication and improvement of orphan crops feasible. However, the generation of new crops or improved crop varieties using traditional breeding techniques requires a lengthy process of recurrent selection, which can take many years (Gorjanc et al., 2018). One of the limiting factors in the process is the plant generation time, from seed germination to the harvest. The plant generation cycle takes up to 4 months in wheat and barley and even longer in others (Watson et al., 2018). Domestication of new crops would require numerous generations to stack the edited genes before crop release. Speed breeding is a procedure, which accelerates crop generation time by changing growth conditions, such as day length and temperature (Hickey et al., 2017). Growing long-day species under extended photoperiod ( $22 \mathrm{~h}$ light $/ 2 \mathrm{~h}$ dark) and controlled temperature stimulates rapid flowering and maturation. The technology successfully shortened the plant generation time of some of the world's major agri-food crops, such as bread wheat, pasta wheat, barley, and canola (Watson et al., 2018). Production of up to six generations for wheat and barley is documented using speed breeding, which is much more efficient compared to two generations per year in traditional methods. Speed breeding protocols have also been successfully applied to orphan crops, such as chickpea, peanut, grass pea, lentil, and quinoa (O'Connor et al., 2013; Chiurugwi et al., 2019). The successful application of speed breeding to orphan crops indicates its flexibility and possible application for new crop domestication. A combination of speed breeding with our current knowledge about the target genes and genomic tools such as precision genome editing by CRISPR would make the new crop domestication feasible in a short time. Speed breeding can also be paired with genomic selection (GS), allowing further reductions in plant breeding cycles. GS is a modern breeding technology, which uses genome-wide markers to estimate the breeding values (EBV) and allows simultaneous selection for multiple traits. A recent study combined multivariate GS and speed breeding for yield prediction in spring wheat (Watson et al., 2019). Even though the current speed breeding protocols are limited to the long-day species, new protocols are expected for the short-day crops in the near future. Coupling speed breeding with genomics will make the GS for breeding and de novo domestication feasible.

\section{High-Throughput Phenotyping}

Plant phenotyping refers to the measurement of any morphological or physiological characteristics of plants. The phenotype can result from the action of individual genes, gene-by-gene, or gene-by-environment interactions. Many agronomically essential traits, such as yield and its components and drought/salt tolerance, are controlled by multiple genes with small effects and their interactions with the environment (Mickelbart et al., 2015).
For practical reasons, many research groups focus on a controlled environment to grow plants and study their response to biotic and abiotic stresses (Velásquez et al., 2018). This includes stress induced by temperature, humidity, light, and other environmental factors. However, in farming, the environment and microclimate change dynamically during the day and affect the plant unevenly, for example due to shading. Moreover, controlled light conditions are hardly equivalent to the irradiance levels and spectral quality typical of natural sun conditions. There is a great need to study plant stresses in dynamic environmental conditions to thoroughly understand the complete picture of plant-stress responses. As the genotypic information is now available for hundreds or thousands of breeding lines in different species, collection and analysis of the corresponding high-throughput phenotyping data is one of the significant tasks ahead (Araus et al., 2018).

High-throughput phenotyping platforms, which employ robotics and spectral-based imaging technologies, are rapid and reliable (Galvez et al., 2019). The main limitation is the controlled environment, which is different from the natural growth conditions in the field. The introduction of hyperspectral imaging technology combined with drones and manned aircrafts provides an opportunity for high-throughput in-field phenotyping of traits, such as canopy temperature, chlorophyll fluorescence, as well as other biochemical plant characteristics (Camino et al., 2019). This technology increases the resolution and accuracy of measurements and is becoming cost-effective. The main challenge of using airborne platforms would be the analysis of large quantity of data in a short time frame (Singh et al., 2016; Taghavi Namin et al., 2018). However, machine learning based methods have shown promise in high-throughput phenotyping data processing. In-field high-throughput phenotyping is perfectly suited for evaluation of the complex physiological traits such as abiotic stresses tolerance.

\section{CONCLUSION}

Recent advances in genome sequencing, assembly, and annotation allowed unprecedented access to crop plant genomic information. High-throughput phenotyping techniques have been significantly advanced through the introduction of hyperspectral cameras and specialized processing software. Integration of genomic and phenomic data provides an opportunity to identify new agronomically relevant genes and characterize their functions. This knowledge has direct practical implications and can be translated to crop plant improvement using genome editing. While genome editing is currently applied in major crops and model plants, the technique has the potential to accelerate de novo domestication and allow rapid improvement of orphan crop plants, targeting the current and future climate challenges. The success of genomics in crop improvement is also influenced by the type of trait under investigation. For example, traits strongly affected by the environment and the interaction between genotype and the environment are more challenging to study and modify.

Disease resistance and dwarfing genes were introduced into crops such as wheat and rice during the green revolution (Khush, 2001). 


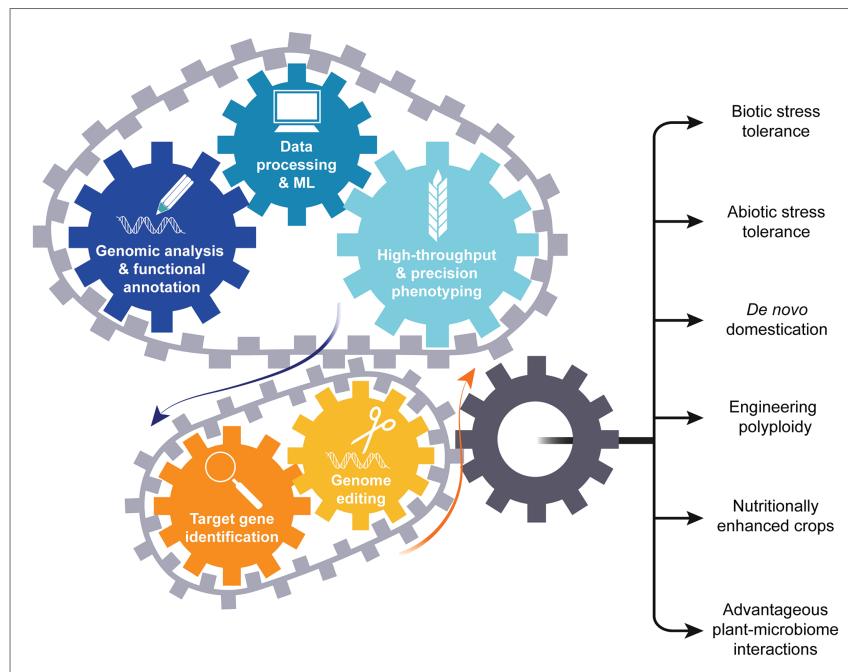

FIGURE 7 | Genomics drives development of climate change resilient crops. Knowledge obtained from genomics and high-throughput phenotyping drives candidate gene selection. Candidate genes can then be modified using genome editing resulting in generation of improved crop types.

\section{REFERENCES}

Adrian, J., Farrona, S., Reimer, J. J., Albani, M. C., Coupland, G., and Turck, F. (2010). Cis-regulatory elements and chromatin state coordinately control temporal and spatial expression of FLOWERING LOCUS T in Arabidopsis. Plant Cell 22, 1425-1440. doi: 10.1105/tpc.110.074682

Appels, R., Eversole, K., Feuillet, C., Keller, B., Rogers, J., Stein, N., et al. (2018). Shifting the limits in wheat research and breeding using a fully annotated reference genome. Science 361:eaar7191. doi: 10.1126/science.aar7191

Araus, J. L., Kefauver, S. C., Zaman-Allah, M., Olsen, M. S., and Cairns, J. E. (2018). Translating high-throughput phenotyping into genetic gain. Trends Plant Sci. 23, 451-466. doi: 10.1016/j.tplants.2018.02.001

Avni, R., Nave, M., Barad, O., Baruch, K., Twardziok, S. O., Gundlach, H., et al. (2017). Wild emmer genome architecture and diversity elucidate wheat evolution and domestication. Science 357, 93-97. doi: 10.1126/science.aan0032

Bajic, M., Maher, K. A., and Deal, R. B. (2018). "Identification of open chromatin regions in plant genomes using ATAC-Seq" in Plant chromatin dynamics: Methods and protocols. eds. M. Bemer and C. Baroux (New York, NY: Springer New York), 183-201.

Barford, E. (2013). Crop pests advancing with global warming. Nature doi: 10.1038/nature.2013.13644

Basenko, E. Y., Pulman, J. A., Shanmugasundram, A., Harb, O. S., Crouch, K., Starns, D., et al. (2018). FungiDB: an integrated bioinformatic resource for fungi and oomycetes. J. fungi 4:39. doi: 10.3390/jof4010039

Belser, C., Istace, B., Denis, E., Dubarry, M., Baurens, F. -C., Falentin, C., et al. (2018). Chromosome-scale assemblies of plant genomes using nanopore long reads and optical maps. Nat. Plants 4, 879-887. doi: 10.1038/ s41477-018-0289-4

Berendsen, R. L., Pieterse, C. M. J., and Bakker, P. A. H. M. (2012). The rhizosphere microbiome and plant health. Trends Plant Sci. 17, 478-486. doi: 10.1016/j.tplants.2012.04.001

Bertioli, D. J. (2019). The origin and evolution of a favorite fruit. Nat. Genet. 51, 372-373. doi: 10.1038/s41588-019-0365-3

Bird, K. A., Vanburen, R., Puzey, J. R., and Edger, P. P. (2018). The causes and consequences of subgenome dominance in hybrids and recent polyploids. New Phytol. 220, 87-93. doi: 10.1111/nph.15256

Blake, V. C., Birkett, C., Matthews, D. E., Hane, D. L., Bradbury, P., and Jannink, J. -L. (2016). The Triticeae toolbox: combining phenotype and genotype data to advance small-grains breeding. Plant Genome 9. doi: 10.3835/ plantgenome2014.12.0099
Breeders developed the high yielding varieties using the extra supply of nitrogen fertilizers in the presence of sufficient water under the climate conditions of the 1950-1960's. The equation is different today as climate change causes water shortages and temperature increases. However, the information gained from genomics and phenomics will drive candidate gene identification and enable genome editing (Figure 7), initiating the new crop plant breeding revolution.

\section{AUTHOR CONTRIBUTIONS}

MP and AG contributed equally. All authors contributed to the article and approved the submitted version.

\section{FUNDING}

This work is supported by the School of Agriculture and Food internal fund at the University of Melbourne to MP and McKenzie Fellowship scheme to AG.

Bothmer, R., Jacobsen, N., Baden, C., Jørgensen, R., and Linde-Laursen, I (1995). An ecogeographical study of the genus Hordeum. Rome: International Plant Genetic Resources Institute.

Boykin, L. M., Sseruwagi, P., Alicai, T., Ateka, E., Mohammed, I. U., Stanton, J. L. et al. (2019). Tree lab: portable genomics for early detection of plant viruses and pests in sub-Saharan Africa. Genes 10:632. doi: 10.3390/genes10090632

Brozynska, M., Furtado, A., and Henry, R. J. (2016). Genomics of crop wild relatives: expanding the gene pool for crop improvement. Plant Biotechnol. J. 14, 1070-1085. doi: 10.1111/pbi.12454

Camino, C., Gonzalez-Dugo, V., Hernandez, P., and Zarco-Tejada, P. J. (2019). Radiative transfer Vcmax estimation from hyperspectral imagery and SIF retrievals to assess photosynthetic performance in rainfed and irrigated plant phenotyping trials. Remote Sens. Environ. 231:111186. doi: 10.1016/j.rse.2019.05.005

Campbell, M. S., Law, M., Holt, C., Stein, J. C., Moghe, G. D., Hufnagel, D. E., et al. (2014). MAKER-P: a tool kit for the rapid creation, management, and quality control of plant genome annotations. Plant Physiol. 164, 513-524. doi: $10.1104 /$ pp.113.230144

Chagas, F. O., Pessotti, R. C., Caraballo-Rodriguez, A. M., and Pupo, M. T. (2018). Chemical signaling involved in plant-microbe interactions. Chem. Soc. Rev. 47, 1652-1704. doi: 10.1039/C7CS00343A

Chakraborty, S. (2013). Migrate or evolve: options for plant pathogens under climate change. Glob. Chang. Biol. 19, 1985-2000. doi: 10.1111/gcb.12205

Chen, Z. J. (2010). Molecular mechanisms of polyploidy and hybrid vigor Trends Plant Sci. 15, 57-71. doi: 10.1016/j.tplants.2009.12.003

Chen, F., Dong, W., Zhang, J., Guo, X., Chen, J., Wang, Z., et al. (2018). The sequenced angiosperm genomes and genome databases. Front. Plant Sci. 9:418. doi: 10.3389/fpls.2018.00418

Chen, G. X., Komatsudu, T., Pourkheirandish, M., Sameri, M., Sato, K., Krugman, T., et al. (2009). Mapping of the eibil gene responsible for the drought hypersensitive cuticle in wild barley (Hordeum spontaneum). Breed. Sci. 59, 21-26. doi: 10.1270/jsbbs.59.21

Cheng, C. -Y., Krishnakumar, V., Chan, A. P., Thibaud-Nissen, F., Schobel, S., and Town, C. D. (2017). Araport11: a complete reannotation of the Arabidopsis thaliana reference genome. Plant J. 89, 789-804. doi: 10.1111/tpj.13415

Cheng, S., Melkonian, M., Smith, S. A., Brockington, S., Archibald, J. M., Delaux, P. -M., et al. (2018). 10KP: a phylodiverse genome sequencing plan. GigaScience 7, 1-9. doi: 10.1093/gigascience/giy013

Chiang, C., Scott, A. J., Davis, J. R., Tsang, E. K., Li, X., Kim, Y., et al. (2017). The impact of structural variation on human gene expression. Nat. Genet 49, 692-699. doi: 10.1038/ng.3834 
Chiurugwi, T., Kemp, S., Powell, W., and Hickey, L. T. (2019). Speed breeding orphan crops. Theor. Appl. Genet. 132, 607-616. doi: 10.1007/s00122-018-3202-7

Chua, Y. L., Watson, L. A., and Gray, J. C. (2003). The transcriptional enhancer of the pea plastocyanin gene associates with the nuclear matrix and regulates gene expression through histone acetylation. Plant Cell 15, 1468-1479. doi: $10.1105 /$ tpc. 011825

Clark, R. M., Linton, E., Messing, J., and Doebley, J. F. (2004). Pattern of diversity in the genomic region near the maize domestication gene tb1. Proc. Natl. Acad. Sci. U. S. A. 101, 700-707. doi: 10.1073/pnas.2237049100

Comai, L. (2005). The advantages and disadvantages of being polyploid. Nat. Rev. Genet. 6, 836-846. doi: 10.1038/nrg1711

Contreras-Moreira, B., Cantalapiedra, C. P., García-Pereira, M. J., Gordon, S. P., Vogel, J. P., Igartua, E., et al. (2017). Analysis of plant pan-genomes and transcriptomes with GET_HOMOLOGUES-EST, a clustering solution for sequences of the same species. Front. Plant Sci. 8:184. doi: 10.3389/ fpls.2017.00184

Cook, R. J. (2006). Toward cropping systems that enhance productivity and sustainability. Proc. Natl. Acad. Sci. U. S. A. 103, 18389-18394. doi: 10.1073/ pnas. 0605946103

Cook, D. E., Valle-Inclan, J. E., Pajoro, A., Rovenich, H., Thomma, B. P. H. J., and Faino, L. (2019). Long-read annotation: automated eukaryotic genome annotation based on long-read cDNA sequencing. Plant Physiol. 179, 38-54. doi: $10.1104 /$ pp. 18.00848

Corneillie, S., De Storme, N., Van Acker, R., Fangel, J. U., De Bruyne, M., De Rycke, R., et al. (2019). Polyploidy affects plant growth and alters cell wall composition. Plant Physiol. 179, 74-87. doi: 10.1104/pp.18.00967

Dellapenna, D. (1999). Nutritional genomics: manipulating plant micronutrients to improve human health. Science 285, 375-379. doi: 10.1126/science. 285.5426.375

Demorest, Z. L., Coffman, A., Baltes, N. J., Stoddard, T. J., Clasen, B. M., Luo, S., et al. (2016). Direct stacking of sequence-specific nuclease-induced mutations to produce high oleic and low linolenic soybean oil. BMC Plant Biol. 16:225. doi: 10.1186/s12870-016-0906-1

Dempewolf, H., Baute, G., Anderson, J., Kilian, B., Smith, C., and Guarino, L. (2017). Past and future use of wild relatives in crop breeding. Crop Sci. 57, 1070-1082. doi: 10.2135/cropsci2016.10.0885

Devos, K. M. (2005). Updating the 'Crop circle'. Curr. Opin. Plant Biol. 8, 155-162. doi: 10.1016/j.pbi.2005.01.005

Ding, J., Lu, Q., Ouyang, Y., Mao, H., Zhang, P., Yao, J., et al. (2012). A long non-coding RNA regulates photoperiod-sensitive male sterility, an essential component of hybrid rice. Proc. Natl. Acad. Sci. U. S. A. 109, 2654-2659. doi: $10.1073 /$ pnas.1121374109

Dodds, P. N., and Rathjen, J. P. (2010). Plant immunity: towards an integrated view of plant-pathogen interactions. Nat. Rev. Genet. 11, 539-548. doi: $10.1038 / \mathrm{nrg} 2812$

Doebley, J. F., Gaut, B. S., and Smith, B. D. (2006). The molecular genetics of crop domestication. Cell 127, 1309-1321. doi: 10.1016/j.cell. 2006.12.006

Dong, Y., Yang, X., Liu, J., Wang, B. -H., Liu, B. -L., and Wang, Y. -Z. (2014). Pod shattering resistance associated with domestication is mediated by a NAC gene in soybean. Nat. Commun. 5:3352. doi: 10.1038/ncomms4352

Dubcovsky, J., and Dvorak, J. (2007). Genome plasticity a key factor in the success of polyploid wheat under domestication. Science 316, 1862-1866. doi: $10.1126 /$ science. 1143986

Edger, P. P., Poorten, T. J., Vanburen, R., Hardigan, M. A., Colle, M., Mckain, M. R., et al. (2019). Origin and evolution of the octoploid strawberry genome. Nat. Genet. 51, 541-547. doi: 10.1038/s41588-019-0356-4

Edger, P. P., Smith, R., Mckain, M. R., Cooley, A. M., Vallejo-Marin, M., Yuan, Y., et al. (2017). Subgenome dominance in an interspecific hybrid, synthetic allopolyploid, and a 140-year-old naturally established neo-allopolyploid monkeyflower. Plant Cell 29, 2150-2167. doi: 10.1105/tpc.17.00010

Eggertsson, H. P., Jonsson, H., Kristmundsdottir, S., Hjartarson, E., Kehr, B., Masson, G., et al. (2017). Graphtyper enables population-scale genotyping using pangenome graphs. Nat. Genet. 49, 1654-1660. doi: 10.1038/ng.3964

Faria, N. R., Sabino, E. C., Nunes, M. R. T., Alcantara, L. C. J., Loman, N. J., and Pybus, O. G. (2016). Mobile real-time surveillance of Zika virus in Brazil. Genome Med. 8:97. doi: 10.1186/s13073-016-0356-2

Fellbaum, C. R., Gachomo, E. W., Beesetty, Y., Choudhari, S., Strahan, G. D., Pfeffer, P. E., et al. (2012). Carbon availability triggers fungal nitrogen uptake and transport in arbuscular mycorrhizal symbiosis. Proc. Natl. Acad. Sci. U. S. A. 109, 2666-2671. doi: 10.1073/pnas.1118650109

Feuillet, C., Langridge, P., and Waugh, R. (2008). Cereal breeding takes a walk on the wild side. Trends Genet. 24, 24-32. doi: 10.1016/j.tig.2007.11.001

Fitzpatrick, C. R., Copeland, J., Wang, P. W., Guttman, D. S., Kotanen, P. M., and Johnson, M. T. J. (2018). Assembly and ecological function of the root microbiome across angiosperm plant species. Proc. Natl. Acad. Sci. U. S. A. 115, E1157-E1165. doi: 10.1073/pnas.1717617115

Frary, A., Nesbitt, T. C., Grandillo, S., Knaap, E., Cong, B., Liu, J., et al. (2000). fw2.2: a quantitative trait locus key to the evolution of tomato fruit size. Science 289, 85-88. doi: 10.1126/science.289.5476.85

Fu, D., Uauy, C., Distelfeld, A., Blechl, A., Epstein, L., Chen, X., et al. (2009). A kinase-START gene confers temperature-dependent resistance to wheat stripe rust. Science 323, 1357-1360. doi: 10.1126/science.1166289

Fuentes, R. R., Chebotarov, D., Duitama, J., Smith, S., De La Hoz, J. F., Mohiyuddin, M., et al. (2019). Structural variants in 3000 rice genomes. Genome Res. 29, 870-880. doi: 10.1101/gr.241240.118

Gabur, I., Chawla, H. S., Liu, X., Kumar, V., Faure, S., Von Tiedemann, A., et al. (2018). Finding invisible quantitative trait loci with missing data. Plant Biotechnol. J. 16, 2102-2112. doi: 10.1111/pbi.12942

Gaebelein, R., Schiessl, S. V., Samans, B., Batley, J., and Mason, A. S. (2019). Inherited allelic variants and novel karyotype changes influence fertility and genome stability in Brassica allohexaploids. New Phytol. 223, 965-978. doi: 10.1111/nph.15804

Gage, J. L., Vaillancourt, B., Hamilton, J. P., Manrique-Carpintero, N. C., Gustafson, T. J., Barry, K., et al. (2019). Multiple maize reference genomes impact the identification of variants by genome-wide association study in a diverse inbred panel. Plant Genome 12. doi: 10.3835/plantgenome2018.09.006

Galvez, S., Merida-Garcia, R., Camino, C., Borrill, P., Abrouk, M., Ramirez-Gonzalez, R. H., et al. (2019). Hotspots in the genomic architecture of field drought responses in wheat as breeding targets. Funct. Integr. Genomic. 19, 295-309. doi: 10.1007/s10142-018-0639-3

Gao, L., Gonda, I., Sun, H., Ma, Q., Bao, K., Tieman, D. M., et al. (2019). The tomato pan-genome uncovers new genes and a rare allele regulating fruit flavor. Nat. Genet. 51, 1044-1051. doi: 10.1038/s41588-019-0410-2

Gao, H., Wang, Y., Li, W., Gu, Y., Lai, Y., Bi, Y., et al. (2018). Transcriptomic comparison reveals genetic variation potentially underlying seed developmental evolution of soybeans. J. Exp. Bot. 69, 5089-5104. doi: 10.1093/jxb/ery291

Garbeva, P., Van Elsas, J. D., and Van Veen, J. A. (2008). Rhizosphere microbial community and its response to plant species and soil history. Plant Soil 302, 19-32. doi: 10.1007/s11104-007-9432-0

Garrison, E., Siren, J., Novak, A. M., Hickey, G., Eizenga, J. M., Dawson, E. T., et al. (2018). Variation graph toolkit improves read mapping by representing genetic variation in the reference. Nat. Biotechnol. 36, 875-879. doi: 10.1038/ nbt. 4227

Godfray, H. C. J., Crute, I. R., Haddad, L., Lawrence, D., Muir, J. F., Nisbett, N., et al. (2010). The future of the global food system. Philos. Trans. $R$ Soc. Lond. B Biol. Sci. 365, 2769-2777. doi: 10.1098/rstb.2010.0180

Golicz, A. A., Batley, J., and Edwards, D. (2016a). Towards plant pangenomics. Plant Biotechnol. J. 14, 1099-1105. doi: 10.1111/pbi.12499

Golicz, A. A., Bayer, P. E., Barker, G. C., Edger, P. P., Kim, H., Martinez, P. A., et al. (2016b). The pangenome of an agronomically important crop plant Brassica oleracea. Nat. Commun. 7:13390. doi: 10.1038/ncomms13390

Golicz, A. A., Bayer, P. E., Bhalla, P. L., Batley, J., and Edwards, D. (2020). Pangenomics comes of age: from bacteria to plant and animal applications. Trends Genet. 36, 132-145. doi: 10.1016/j.tig.2019.11.006

Golicz, A. A., Bhalla, P. L., and Singh, M. B. (2018a). IncRNAs in plant and animal sexual reproduction. Trends Plant Sci. 23, 195-205. doi: 10.1016/j. tplants.2017.12.009

Golicz, A. A., Bhalla, P. L., and Singh, M. B. (2018b). MCRiceRepGP: a framework for the identification of genes associated with sexual reproduction in rice. Plant J. 96, 188-202. doi: 10.1111/tpj.14019

Gordon, S. P., Contreras-Moreira, B., Woods, D. P., Des Marais, D. L., Burgess, D., Shu, S., et al. (2017). Extensive gene content variation in the Brachypodium distachyon pan-genome correlates with population structure. Nat. Commun. 8:2184. doi: $10.1038 /$ s41467-017-02292-8

Gorjanc, G., Gaynor, R. C., and Hickey, J. M. (2018). Optimal cross selection for long-term genetic gain in two-part programs with rapid recurrent genomic selection. Theor. Appl. Genet. 131, 1953-1966. doi: 10.1007/s00122-018-3125-3 
Grant, D., Nelson, R. T., Cannon, S. B., and Shoemaker, R. C. (2010). SoyBase, the USDA-ARS soybean genetics and genomics database. Nucleic Acids Res. 38, D843-D846. doi: 10.1093/nar/gkp798

Grassini, P., Eskridge, K. M., and Cassman, K. G. (2013). Distinguishing between yield advances and yield plateaus in historical crop production trends. Nat. Commun. 4:2918. doi: 10.1038/ncomms3918

Haider, N. (2013). The origin of the B-genome of bread wheat (Triticum aestivum L.). Russ. J. Genet. 49, 263-274. doi: 10.1134/S1022795413030071

Hajjar, R., Jarvis, D. I., and Gemmill-Herren, B. (2008). The utility of crop genetic diversity in maintaining ecosystem services. Agric. Ecosyst. Environ. 123, 261-270. doi: 10.1016/j.agee.2007.08.003

Hartmann, F. E., Sánchez-Vallet, A., Mcdonald, B. A., and Croll, D. (2017). A fungal wheat pathogen evolved host specialization by extensive chromosomal rearrangements. ISME J. 11, 1189-1204. doi: 10.1038/ismej.2016.196

Hassani-Pak, K., and Rawlings, C. (2017). Knowledge discovery in biological databases for revealing candidate genes linked to complex phenotypes. J. Integr. Bioinform. 14:20160002. doi: 10.1515/jib-2016-0002

Haun, W., Coffman, A., Clasen, B. M., Demorest, Z. L., Lowy, A., Ray, E., et al. (2014). Improved soybean oil quality by targeted mutagenesis of the fatty acid desaturase 2 gene family. Plant Biotechnol. J. 12, 934-940. doi: 10.1111/pbi.12201

Hefferon, K. L. (2015). Nutritionally enhanced food crops; progress and perspectives. Int. J. Mol. Sci. 16, 3895-3914. doi: 10.3390/ijms16023895

Hickey, L. T., German, S. E., Pereyra, S. A., Diaz, J. E., Ziems, L. A., Fowler, R. A., et al. (2017). Speed breeding for multiple disease resistance in barley. Euphytica 213:64. doi: 10.1007/s10681-016-1803-2

Huang, L., Dong, H., Zhou, D., Li, M., Liu, Y., Zhang, F., et al. (2018). Systematic identification of long non-coding RNAs during pollen development and fertilization in Brassica rapa. Plant J. 96, 203-222. doi: 10.1111/tpj.14016

Huang, X., Kurata, N., Wei, X., Wang, Z. -X., Wang, A., Zhao, Q., et al. (2012). A map of rice genome variation reveals the origin of cultivated rice. Nature 490, 497-501. doi: 10.1038/nature11532

Hufford, M. B., Lubinksy, P., Pyhäjärvi, T., Devengenzo, M. T., Ellstrand, N. C., and Ross-Ibarra, J. (2013). The genomic signature of crop-wild introgression in maize. PLoS Genet. 9:e1003477. doi: 10.1371/annotation/2eef7b5b-29b2-41 2f-8472-8fd7f9bd65ab

Hurgobin, B., Golicz, A. A., Bayer, P. E., Chan, C. K. K., Tirnaz, S., Dolatabadian, A., et al. (2018). Homoeologous exchange is a major cause of gene presence/ absence variation in the amphidiploid Brassica napus. Plant Biotechnol. J. 16, 1265-1274. doi: 10.1111/pbi.12867

Hyten, D. L., Song, Q., Zhu, Y., Choi, I. -Y., Nelson, R. L., Costa, J. M., et al. (2006). Impacts of genetic bottlenecks on soybean genome diversity. Proc. Natl. Acad. Sci. U. S. A. 103, 16666-16671. doi: 10.1073/pnas.0604379103

Ishimaru, K., Hirotsu, N., Madoka, Y., Murakami, N., Hara, N., Onodera, H., et al. (2013). Loss of function of the IAA-glucose hydrolase gene TGW6 enhances rice grain weight and increases yield. Nat. Genet. 45, 707-711. doi: $10.1038 /$ ng.2612

Jansson, J. K., and Hofmockel, K. S. (2018). The soil microbiome-from metagenomics to metaphenomics. Curr. Opin. Microbiol. 43, 162-168. doi: 10.1016/j.mib.2018.01.013

Jeong, J. -J., Sang, M. K., Pathiraja, D., Park, B., Choi, I. -G., and Kim, K. D. (2018). Draft genome sequence of phosphate-solubilizing Chryseobacterium sp. strain ISE14, a biocontrol and plant growth-promoting rhizobacterium isolated from cucumber. Genome Announc. 6, e00612-e00618. doi: 10.1128/ genomeA.00612-18

Jiao, Y., and Paterson, A. H. (2014). Polyploidy-associated genome modifications during land plant evolution. Philos. Trans. R Soc. Lond. B Biol. Sci. 369:20130355. doi: $10.1098 /$ rstb.2013.0355

Johnson, C., Conrad, L. J., Patel, R., Anderson, S., Li, C., Pereira, A., et al. (2018). Reproductive long intergenic noncoding RNAs exhibit male gamete specificity and polycomb repressive complex 2-mediated repression. Plant Physiol. 177, 1198-1217. doi: 10.1104/pp.17.01269

Joly-Lopez, Z., Flowers, J. M., and Purugganan, M. D. (2016). Developing maps of fitness consequences for plant genomes. Curr. Opin. Plant Biol. 30, 101-107. doi: 10.1016/j.pbi.2016.02.008

Jones, J. D., and Dangl, J. L. (2006). The plant immune system. Nature 444, 323-329. doi: 10.1038/nature05286

Katche, E., Quezada-Martinez, D., Katche, E. I., Vasquez-Teuber, P., and Mason, A. S. (2019). Interspecific hybridization for Brassica crop improvement. Crop Breed. Genet. Genom. 1:e190007. doi: 10.20900/cbgg20190007
Kelley, D. R., Snoek, J., and Rinn, J. L. (2016). Basset: learning the regulatory code of the accessible genome with deep convolutional neural networks. Genome Res. 26, 990-999. doi: 10.1101/gr.200535.115

Khoury, C. K., Bjorkman, A. D., Dempewolf, H., Ramirez-Villegas, J., Guarino, L., Jarvis, A., et al. (2014). Increasing homogeneity in global food supplies and the implications for food security. Proc. Natl. Acad. Sci. U. S. A. 111, 4001-4006. doi: 10.1073/pnas.1313490111

Khush, G. S. (2001). Green revolution: the way forward. Nat. Rev. Genet. 2, 815-822. doi: 10.1038/35093585

Kim, D., Paggi, J. M., Park, C., Bennett, C., and Salzberg, S. L. (2019). Graph-based genome alignment and genotyping with HISAT2 and HISATgenotype. Nat. Biotechnol. 37, 907-915. doi: 10.1038/s41587-019-0201-4

Klasberg, S., Bitard-Feildel, T., and Mallet, L. (2016). Computational identification of novel genes: current and future perspectives. Bioinform. Biol. Insights 10, 121-131. doi: 10.4137/BBI.S39950

Kofsky, J., Zhang, H., and Song, B. -H. (2018). The untapped genetic reservoir: the past, current, and future applications of the wild soybean (Glycine soja). Front. Plant Sci. 9:949. doi: 10.3389/fpls.2018.00949

Komatsuda, T., Pourkheirandish, M., He, C., Azhaguvel, P., Kanamori, H., Perovic, D., et al. (2007). Six-rowed barley originated from a mutation in a homeodomain-leucine zipper I-class homeobox gene. Proc. Natl. Acad. Sci. U. S. A. 104, 1424-1429. doi: 10.1073/pnas.0608580104

Konishi, S., Izawa, T., Lin, S. Y., Ebana, K., Fukuta, Y., Sasaki, T., et al. (2006). An SNP caused loss of seed shattering during rice domestication. Science 312, 1392-1396. doi: 10.1126/science.1126410

Krattinger, S. G., Sucher, J., Selter, L. L., Chauhan, H., Zhou, B., Tang, M., et al. (2016). The wheat durable, multipathogen resistance gene Lr34 confers partial blast resistance in rice. Plant Biotechnol. J. 14, 1261-1268. doi: 10.1111/ pbi.12491

Leach, J. E., Triplett, L. R., Argueso, C. T., and Trivedi, P. (2017). Communication in the phytobiome. Cell 169, 587-596. doi: 10.1016/j.cell.2017.04.025

Lemmon, Z. H., Bukowski, R., Sun, Q., and Doebley, J. F. (2014). The role of cis regulatory evolution in maize domestication. PLoS Genet. 10:e1004745. doi: 10.1371/journal.pgen.1004745

Li, C., Chen, G., Mishina, K., Yamaji, N., Ma, J. F., Yukuhiro, F., et al. (2017a). A GDSL-motif esterase/acyltransferase/lipase is responsible for leaf water retention in barley. Plant Direct 1:e00025. doi: 10.1002/pld3.25

Li, Y., Quang, D., and Xie, X. (2017b). "Understanding sequence conservation with deep learning" in Proceedings of the 8th ACM international conference on bioinformatics, computational biology, and health informatics. Boston, Massachusetts, USA: ACM.

Li, C., Wang, A., Ma, X., Pourkheirandish, M., Sakuma, S., Wang, N., et al. (2012). An eceriferum locus, cer-zv, is associated with a defect in cutin responsible for water retention in barley (Hordeum vulgare) leaves. Theor. Appl. Genet. 126, 637-646. doi: 10.1007/s00122-012-2007-3

Li, T., Yang, X., Yu, Y., Si, X., Zhai, X., Zhang, H., et al. (2018). Domestication of wild tomato is accelerated by genome editing. Nat. Biotechnol. 36, 1160-1163. doi: 10.1038/nbt.4273

Li, Y. H., Zhou, G., Ma, J., Jiang, W., Jin, L. G., Zhang, Z., et al. (2014). De novo assembly of soybean wild relatives for pan-genome analysis of diversity and agronomic traits. Nat. Biotechnol. 32, 1045-1052. doi: 10.1038/nbt.2979

Liang, Z., Zhang, K., Chen, K., and Gao, C. (2014). Targeted mutagenesis in Zea mays using TALENs and the CRISPR/Cas system. J. Genet. Genomics 41, 63-68. doi: 10.1016/j.jgg.2013.12.001

Lin, Z., Li, X., Shannon, L. M., Yeh, C. T., Wang, M. L., Bai, G., et al. (2012). Parallel domestication of the shattering1 genes in cereals. Nat. Genet. 44, 720-724. doi: 10.1038/ng.2281

Louwers, M., Bader, R., Haring, M., Van Driel, R., De Laat, W., and Stam, M. (2009). Tissue- and expression level-specific chromatin looping at maize epialleles. Plant Cell 21, 832-842. doi: 10.1105/tpc.108.064329

Lu, Y., Ye, X., Guo, R., Huang, J., Wang, W., Tang, J., et al. (2017). Genome-wide targeted mutagenesis in rice using the CRISPR/Cas9 system. Mol. Plant 10, 1242-1245. doi: 10.1016/j.molp.2017.06.007

Ma, W., Qiu, Z., Song, J., Li, J., Cheng, Q., Zhai, J., et al. (2018). A deep convolutional neural network approach for predicting phenotypes from genotypes. Planta 248, 1307-1318. doi: 10.1007/s00425-018-2976-9

Mago, R., Zhang, P., Vautrin, S., Simkova, H., Bansal, U., Luo, M. C., et al. (2015). The wheat Sr50 gene reveals rich diversity at a cereal disease resistance locus. Nat. Plants 1:15186. doi: 10.1038/nplants.2015.186 
Mammadov, J., Buyyarapu, R., Guttikonda, S. K., Parliament, K., Abdurakhmonov, I. Y., and Kumpatla, S. P. (2018). Wild relatives of maize, rice, cotton, and soybean: treasure troves for tolerance to biotic and abiotic stresses. Front. Plant Sci. 9:886. doi: 10.3389/fpls.2018.00886

Mansueto, L., Fuentes, R. R., Borja, F. N., Detras, J., Abriol-Santos, J. M., Chebotarov, D., et al. (2017). Rice SNP-seek database update: new SNPs, indels, and queries. Nucleic Acids Res. 45, D1075-D1081. doi: 10.1093/nar/ gkw1135

Mascher, M., Gundlach, H., Himmelbach, A., Beier, S., Twardziok, S. O., Wicker, T., et al. (2017). A chromosome conformation capture ordered sequence of the barley genome. Nature 544, 427-433. doi: 10.1038/nature22043

Mendes, R., Kruijt, M., De Bruijn, I., Dekkers, E., Van Der Voort, M., Schneider, J. H. M., et al. (2011). Deciphering the rhizosphere microbiome for disease-suppressive bacteria. Science 332, 1097-1100. doi: 10.1126/science.1203980

Meng, X., Yu, H., Zhang, Y., Zhuang, F., Song, X., Gao, S., et al. (2017). Construction of a genome-wide mutant library in rice using CRISPR/Cas9. Mol. Plant 10, 1238-1241. doi: 10.1016/j.molp.2017.06.006

Menges, M., De Jager, S. M., Gruissem, W., and Murray, J. A. H. (2005). Global analysis of the core cell cycle regulators of Arabidopsis identifies novel genes, reveals multiple and highly specific profiles of expression and provides a coherent model for plant cell cycle control. Plant J. 41, 546-566. doi: 10.1111/j.1365-313X.2004.02319.x

Mickelbart, M. V., Hasegawa, P. M., and Bailey-Serres, J. (2015). Genetic mechanisms of abiotic stress tolerance that translate to crop yield stability. Nat. Rev. Genet. 16, 237-251. doi: 10.1038/nrg3901

Middleton, C. P., Senerchia, N., Stein, N., Akhunov, E. D., Keller, B., Wicker, T., et al. (2014). Sequencing of chloroplast genomes from wheat, barley, rye and their relatives provides a detailed insight into the evolution of the Triticeae tribe. PLoS One 9:e85761. doi: 10.1371/journal.pone.0085761

Migicovsky, Z., and Myles, S. (2017). Exploiting wild relatives for genomicsassisted breeding of perennial crops. Front. Plant Sci. 8:460. doi: 10.3389/ fpls.2017.00460

Milner, S. G., Jost, M., Taketa, S., Mazon, E. R., Himmelbach, A., Oppermann, M., et al. (2019). Genebank genomics highlights the diversity of a global barley collection. Nat. Genet. 51, 319-326. doi: 10.1038/s41588-018-0266-x

Montenegro, J. D., Golicz, A. A., Bayer, P. E., Hurgobin, B., Lee, H., Chan, C. K. K., et al. (2017). The pangenome of hexaploid bread wheat. Plant J. 90, 1007-1013. doi: $10.1111 /$ tpj.13515

Moore, J. W., Herrera-Foessel, S., Lan, C., Schnippenkoetter, W., Ayliffe, M., Huerta-Espino, J., et al. (2015). A recently evolved hexose transporter variant confers resistance to multiple pathogens in wheat. Nat. Genet. 47, 1494-1498. doi: 10.1038/ng.3439

Nelson, R., Wiesner-Hanks, T., Wisser, R., and Balint-Kurti, P. (2018). Navigating complexity to breed disease-resistant crops. Nat. Rev. Genet. 19, 21-33. doi: 10.1038/nrg.2017.82

Ning, S., Wang, N., Sakuma, S., Pourkheirandish, M., Wu, J., Matsumoto, T., et al. (2013). Structure, transcription and post-transcriptional regulation of the bread wheat orthologs of the barley cleistogamy gene Cly1. Theor. Appl. Genet. 126, 1273-1283. doi: 10.1007/s00122-013-2052-6

O'connor, D. J., Wright, G. C., Dieters, M. J., George, D. L., Hunter, M. N., Tatnell, J. R., et al. (2013). Development and Application of Speed Breeding technologies in a commercial peanut breeding program. Peanut Sci. 40, 107-114. doi: 10.3146/PS12-12.1

Oerke, E. C., and Dehne, H. W. (2004). Safeguarding production-losses in major crops and the role of crop protection. Crop Prot. 23, 275-285. doi: 10.1016/j.cropro.2003.10.001

Oka, R., Zicola, J., Weber, B., Anderson, S. N., Hodgman, C., Gent, J. I., et al. (2017). Genome-wide mapping of transcriptional enhancer candidates using DNA and chromatin features in maize. Genome Biol. 18:137. doi: 10.1186/ s13059-017-1273-4

Ormeño-Orrillo, E., Aguilar-Cuba, Y., and Zúñiga-Dávila, D. (2018). Draft genome sequence of Rhizobium sophoriradicis H4, a nitrogen-fixing bacterium associated with the leguminous plant Phaseolus vulgaris on the coast of Peru. Genome Announc. 6, e00241-e00218. doi: 10.1128/genomeA.00241-18

Ou, L., Li, D., Lv, J., Chen, W., Zhang, Z., Li, X., et al. (2018). Pan-genome of cultivated pepper (Capsicum) and its use in gene presence-absence variation analyses. New Phytol. 220, 360-363. doi: 10.1111/nph.15413

Pajoro, A., Madrigal, P., Muiño, J. M., Matus, J. T., Jin, J., Mecchia, M. A., et al. (2014). Dynamics of chromatin accessibility and gene regulation by
MADS-domain transcription factors in flower development. Genome Biol. 15:R41. doi: 10.1186/gb-2014-15-3-r41

Paredes, S. H., Gao, T. X., Law, T. F., Finkel, O. M., Mucyn, T., Teixeira, P. J. P. L., et al. (2018). Design of synthetic bacterial communities for predictable plant phenotypes. PLoS Biol. 16:e2003962. doi: 10.1371/journal.pbio.2003962

Pérez-Jaramillo, J. E., Carrión, V. J., De Hollander, M., and Raaijmakers, J. M. (2018). The wild side of plant microbiomes. Microbiome 6:143. doi: 10.1186/ s40168-018-0519-z

Pimentel, D., Wilson, C., Mccullum, C., Huang, R., Dwen, P., Flack, J., et al. (1997). Economic and environmental benefits of biodiversity. Bioscience 47, 747-757. doi: 10.2307/1313097

Põlme, S., Bahram, M., Jacquemyn, H., Kennedy, P., Kohout, P., Moora, M., et al. (2018). Host preference and network properties in biotrophic plant-fungal associations. New Phytol. 217, 1230-1239. doi: 10.1111/nph.14895

Pourkheirandish, M., Dai, F., Sakuma, S., Kanamori, H., Distelfeld, A., Willcox, G., et al. (2018). On the origin of the non-brittle rachis trait of domesticated Einkorn wheat. Front. Plant Sci. 8:2031. doi: 10.3389/fpls.2017.02031

Pourkheirandish, M., Hensel, G., Kilian, B., Senthil, N., Chen, G., Sameri, M., et al. (2015). Evolution of the grain dispersal system in barley. Cell 162, 527-539. doi: 10.1016/j.cell.2015.07.002

Pourkheirandish, M., Wicker, T., Stein, N., Fujimura, T., and Komatsuda, T. (2007). Analysis of the barley chromosome 2 region containing the sixrowed spike gene vrs1 reveals a breakdown of rice-barley micro collinearity by a transposition. Theor. Appl. Genet. 114, 1357-1365. doi: 10.1007/ s00122-007-0522-4

Pusztahelyi, T., Holb, I. J., and Pocsi, I. (2015). Secondary metabolites in fungus-plant interactions. Front. Plant Sci. 6:573. doi: 10.3389/fpls.2015.00573

Quick, J., Loman, N. J., Duraffour, S., Simpson, J. T., Severi, E., Cowley, L., et al. (2016). Real-time, portable genome sequencing for Ebola surveillance. Nature 530, 228-232. doi: 10.1038/nature16996

Ramsay, L., Comadran, J., Druka, A., Marshall, D. F., Thomas, W. T., Macaulay, M., et al. (2011). INTERMEDIUM-C, a modifier of lateral spikelet fertility in barley, is an ortholog of the maize domestication gene teosinte branched 1 . Nat. Genet. 43, 169-172. doi: 10.1038/ng.745

Ramsey, J., and Schemske, D. W. (1998). Pathways, mechanisms, and rates of polyploid formation in flowering plants. Annu. Rev. Ecol. Syst. 29, 467-501. doi: 10.1146/annurev.ecolsys.29.1.467

Ray, D. K., Mueller, N. D., West, P. C., and Foley, J. A. (2013). Yield trends are insufficient to double global crop production by 2050. PLoS One 8:e66428. doi: 10.1371/journal.pone.0066428

Rodgers-Melnick, E., Vera, D. L., Bass, H. W., and Buckler, E. S. (2016). Open chromatin reveals the functional maize genome. Proc. Natl. Acad. Sci. U. S. A. 113, E3177-E3184. doi: 10.1073/pnas.1525244113

Sakuma, S., Pourkheirandish, M., Matsumoto, T., Koba, T., and Komatsuda, T. (2010). Duplication of a well-conserved homeodomain-leucine zipper transcription factor gene in barley generates a copy with more specific functions. Funct. Integr. Genomic. 10, 123-133. doi: 10.1007/s10142-009-0134-y

Salman-Minkov, A., Sabath, N., and Mayrose, I. (2016). Whole-genome duplication as a key factor in crop domestication. Nat. Plants 2:16115. doi: 10.1038/ nplants.2016.115

Satterthwaite, D., Mcgranahan, G., and Tacoli, C. (2010). Urbanization and its implications for food and farming. Philos. Trans. R Soc. Lond. B Biol. Sci. 365, 2809-2820. doi: 10.1098/rstb.2010.0136

Sattler, M. C., Carvalho, C. R., and Clarindo, W. R. (2016). The polyploidy and its key role in plant breeding. Planta 243, 281-296. doi: 10.1007/ s00425-015-2450-x

Savary, S., Ficke, A., Aubertot, J. N., and Hollier, C. (2012). Crop losses due to diseases and their implications for global food production losses and food security. Food Sec. 4, 519-537. doi: 10.1007/s12571-012-0200-5

Savary, S., Willocquet, L., Pethybridge, S. J., Esker, P., Mcroberts, N., and Nelson, A. (2019). The global burden of pathogens and pests on major food crops. Nat. Ecol. Evol. 3, 430-439. doi: 10.1038/s41559-018-0793-y

Scheben, A., and Edwards, D. (2018). Bottlenecks for genome-edited crops on the road from lab to farm. Genome Biol. 19:178. doi: 10.1186/s13059-018-1555-5

Scheben, A., Wolter, F., Batley, J., Puchta, H., and Edwards, D. (2017). Towards CRISPR/Cas crops-bringing together genomics and genome editing. New Phytol. 216, 682-698. doi: 10.1111/nph.14702

Schnable, J. C. (2019). Genes and gene models, an important distinction. New Phytol. doi: 10.1111/nph.16011 
Shi, J., Ma, X., Zhang, J., Zhou, Y., Liu, M., Huang, L., et al. (2019). Chromosome conformation capture resolved near complete genome assembly of broomcorn millet. Nat. Commun. 10:464. doi: 10.1038/s41467-018-07876-6

Singh, A., Ganapathysubramanian, B., Singh, A. K., and Sarkar, S. (2016). Machine learning for high-throughput stress phenotyping in plants. Trends Plant Sci. 21, 110-124. doi: 10.1016/j.tplants.2015.10.015

Sosso, D., Luo, D., Li, Q. -B., Sasse, J., Yang, J., Gendrot, G., et al. (2015). Seed filling in domesticated maize and rice depends on SWEET-mediated hexose transport. Nat. Genet. 47, 1489-1493. doi: 10.1038/ng.3422

Sperschneider, J., Dodds, P. N., Gardiner, D. M., Manners, J. M., Singh, K. B., and Taylor, J. M. (2015). Advances and challenges in computational prediction of effectors from plant pathogenic fungi. PLoS Pathog. 11:e1004806. doi: 10.1371/journal.ppat.1004806

Springer, N. M., Anderson, S. N., Andorf, C. M., Ahern, K. R., Bai, F., Barad, O., et al. (2018). The maize W22 genome provides a foundation for functional genomics and transposon biology. Nat. Genet. 50, 1282-1288. doi: 10.1038/ s41588-018-0158-0

Stern, D. L., and Orgogozo, V. (2008). The loci of evolution: how predictable is genetic evolution? Evolution 62, 2155-2177. doi: 10.1111/ j.1558-5646.2008.00450.x

Storkey, J., Bruce, T. J. A., Mcmillan, V. E., and Neve, P. (2019). "Chapter 12-the future of sustainable crop protection relies on increased diversity of cropping systems and landscapes" in Agroecosystem diversity. eds. G. Lemaire, P. C. D. F. Carvalho, S. Kronberg and S. Recous (Cambridge, MA, USA: Academic Press), 199-209.

Studer, A., Zhao, Q., Ross-Ibarra, J., and Doebley, J. (2011). Identification of a functional transposon insertion in the maize domestication gene tb1. Nat. Genet. 43, 1160-1163. doi: 10.1038/ng.942

Szadkowski, E., Eber, F., Huteau, V., Lodé, M., Huneau, C., Belcram, H., et al. (2010). The first meiosis of resynthesized Brassica napus, a genome blender. New Phytol. 186, 102-112. doi: 10.1111/j.1469-8137.2010.03182.x

Taghavi Namin, S., Esmaeilzadeh, M., Najafi, M., Brown, T. B., and Borevitz, J. O. (2018). Deep phenotyping: deep learning for temporal phenotype/genotype classification. Plant Methods 14:66. doi: 10.1186/s13007-018-0333-4

Tamayo-Ordóñez, M. C., Espinosa-Barrera, L. A., Tamayo-Ordóñez, Y. J., Ayil-Gutiérrez, B., and Sánchez-Teyer, L. F. (2016). Advances and perspectives in the generation of polyploid plant species. Euphytica 209, 1-22. doi: 10.1007/s10681-016-1646-x

Tang, H., Bowers, J. E., Wang, X., Ming, R., Alam, M., and Paterson, A. H. (2008). Synteny and collinearity in plant genomes. Science 320, 486-488. doi: $10.1126 /$ science. 1153917

Tank, J. G., and Thaker, V. S. (2011). Cyclin dependent kinases and their role in regulation of plant cell cycle. Biol. Plant. 55, 201-212. doi: 10.1007/ s10535-011-0031-9

Tannenbaum, M., Sarusi-Portuguez, A., Krispil, R., Schwartz, M., Loza, O., Benichou, J. I. C., et al. (2018). Regulatory chromatin landscape in Arabidopsis thaliana roots uncovered by coupling INTACT and ATAC-seq. Plant Methods 14:113. doi: 10.1186/s13007-018-0381-9

Tettelin, H., Masignani, V., Cieslewicz, M. J., Donati, C., Medini, D., Ward, N. L., et al. (2005). Genome analysis of multiple pathogenic isolates of Streptococcus agalactiae: implications for the microbial "pan-genome". Proc. Natl. Acad. Sci. U. S. A. 102, 13950-13955. doi: 10.1073/pnas.0506758102

Tian, X., Li, R., Fu, W., Li, Y., Wang, X., Li, M., et al. (2019). Building a sequence map of the pig pan-genome from multiple de novo assemblies and Hi-C data. Sci. China Life Sci. 63, 750-763. doi: 10.1007/ s11427-019-9551-7

Tian, Z., Wang, X., Lee, R., Li, Y., Specht, J. E., Nelson, R. L., et al. (2010). Artificial selection for determinate growth habit in soybean. Proc. Natl. Acad. Sci. U. S. A. 107, 8563-8568. doi: 10.1073/pnas.1000088107

Tiffin, P., and Moeller, D. A. (2006). Molecular evolution of plant immune system genes. Trends Genet. 22, 662-670. doi: 10.1016/j.tig.2006.09.011

Tilman, D., Balzer, C., Hill, J., and Befort, B. L. (2011). Global food demand and the sustainable intensification of agriculture. Proc. Natl. Acad. Sci. U. S. A. 108, 20260-20264. doi: 10.1073/pnas.1116437108

Tilman, D., and Clark, M. (2014). Global diets link environmental sustainability and human health. Nature 515, 518-522. doi: 10.1038/nature13959

Tomlinson, I. (2013). Doubling food production to feed the 9 billion: a critical perspective on a key discourse of food security in the UK. J. Rural. Stud. 29, 81-90. doi: 10.1016/j.jrurstud.2011.09.001
Uauy, C., Distelfeld, A., Fahima, T., Blechl, A., and Dubcovsky, J. (2006). A NAC gene regulating senescence improves grain protein, zinc, and iron content in wheat. Science 314, 1298-1301. doi: 10.1126/science.1133649

Van Bel, M., Bucchini, F., and Vandepoele, K. (2019). Gene space completeness in complex plant genomes. Curr. Opin. Plant Biol. 48, 9-17. doi: 10.1016/j. pbi.2019.01.001

Varshney, R. K., Saxena, R. K., Upadhyaya, H. D., Khan, A. W., Yu, Y., Kim, C., et al. (2017). Whole-genome resequencing of 292 pigeonpea accessions identifies genomic regions associated with domestication and agronomic traits. Nat. Genet. 49, 1082-1088. doi: 10.1038/ng.3872

Varshney, R. K., Singh, V. K., Kumar, A., Powell, W., and Sorrells, M. E. (2018). Can genomics deliver climate-change ready crops? Curr. Opin. Plant Biol. 45, 205-211. doi: 10.1016/j.pbi.2018.03.007

Varshney, R. K., Thudi, M., Roorkiwal, M., He, W., Upadhyaya, H. D., Yang, W., et al. (2019). Resequencing of 429 chickpea accessions from 45 countries provides insights into genome diversity, domestication and agronomic traits. Nat. Genet. 51, 857-864. doi: 10.1038/s41588-019-0401-3

Velásquez, A. C., Castroverde, C. D. M., and He, S. Y. (2018). Plant-pathogen warfare under changing climate conditions. Curr. Biol. 28, R619-R634. doi: 10.1016/j.cub.2018.03.054

Venturi, V., and Keel, C. (2016). Signaling in the rhizosphere. Trends Plant Sci. 21, 187-198. doi: 10.1016/j.tplants.2016.01.005

Veresoglou, S. D., and Rillig, M. C. (2014). Do closely related plants host similar arbuscular mycorrhizal fungal communities? A meta-analysis. Plant Soil 377, 395-406. doi: 10.1007/s11104-013-2008-2

Vincent, H., Wiersema, J., Kell, S., Fielder, H., Dobbie, S., Castañeda-Álvarez, N. P., et al. (2013). A prioritized crop wild relative inventory to help underpin global food security. Biol. Conserv. 167, 265-275. doi: 10.1016/j.biocon. ssss2013.08.011

Waltz, E. (2018). With a free pass, CRISPR-edited plants reach market in record time. Nat. Biotechnol. 36, 6-7. doi: 10.1038/nbt0118-6b

Wan, L., Koeck, M., Williams, S. J., Ashton, A. R., Lawrence, G. J., Sakakibara, H., et al. (2019). Structural and functional insights into the modulation of the activity of a flax cytokinin oxidase by flax rust effector AvrL567-A. Mol. Plant Pathol. 20, 211-222. doi: 10.1111/mpp.12749

Wang, Y., Jiang, R., and Wong, W. H. (2016). Modeling the causal regulatory network by integrating chromatin accessibility and transcriptome data. Natl. Sci. Rev. 3, 240-251. doi: 10.1093/nsr/nww025

Wang, M., Li, W., Fang, C., Xu, F., Liu, Y., Wang, Z., et al. (2018a). Parallel selection on a dormancy gene during domestication of crops from multiple families. Nat. Genet. 50, 1435-1441. doi: 10.1038/s41588-018-0229-2

Wang, W., Mauleon, R., Hu, Z., Chebotarov, D., Tai, S., Wu, Z., et al. (2018b). Genomic variation in 3,010 diverse accessions of Asian cultivated rice. Nature 557, 43-49. doi: 10.1038/s41586-018-0063-9

Wang, M., Tu, L., Lin, M., Lin, Z., Wang, P., Yang, Q., et al. (2017). Asymmetric subgenome selection and cis-regulatory divergence during cotton domestication. Nat. Genet. 49, 579-587. doi: 10.1038/ng.3807

Watson, A., Ghosh, S., Williams, M. J., Cuddy, W. S., Simmonds, J., Rey, M. D., et al. (2018). Speed breeding is a powerful tool to accelerate crop research and breeding. Nat. Plants 4, 23-29. doi: 10.1038/s41477-017-0083-8

Watson, A., Hickey, L. T., Christopher, J., Rutkoski, J., Poland, J., and Hayes, B. J. (2019). Multivariate genomic selection and potential of rapid indirect selection with speed breeding in spring wheat. Crop Sci. 59, 1945-1959. doi: 10.2135/ cropsci2018.12.0757

Weber, B., Zicola, J., Oka, R., and Stam, M. (2016). Plant enhancers: a call for discovery. Trends Plant Sci. 21, 974-987. doi: 10.1016/j.tplants.2016.07.013

Wei, Z., Gu, Y., Friman, V. -P., Kowalchuk, G. A., Xu, Y., Shen, Q., et al. (2019). Initial soil microbiome composition and functioning predetermine future plant health. Sci. Adv. 5:eaaw0759. doi: 10.1126/sciadv.aaw0759

Welch, R. M., and Graham, R. D. (2002). Breeding crops for enhanced micronutrient content. Plant Soil 245, 205-214. doi: 10.1023/A:1020668100330

Westerbergh, A., Lerceteau-Köhler, E., Sameri, M., Bedada, G., and Lundquist, P. -O. (2018). Towards the development of perennial barley for cold temperate climates-evaluation of wild barley relatives as genetic resources. Sustainability 10:1969. doi: 10.3390/su10061969

Wu, D., Liang, Z., Yan, T., Xu, Y., Xuan, L., Tang, J., et al. (2019). Wholegenome resequencing of a worldwide collection of rapeseed accessions reveals the genetic basis of ecotype divergence. Mol. Plant 12, 30-43. doi: 10.1016/j. molp.2018.11.007 
Xu, C., and Jackson, S. A. (2019). Machine learning and complex biological data. Genome Biol. 20:76. doi: 10.1186/s13059-019-1689-0

Xu, X., Liu, X., Ge, S., Jensen, J. D., Hu, F., Li, X., et al. (2012). Resequencing 50 accessions of cultivated and wild rice yields markers for identifying agronomically important genes. Nat. Biotechnol. 30, 105-111. doi: 10.1038/ nbt. 2050

Yan, W., Chen, D., Schumacher, J., Durantini, D., Engelhorn, J., Chen, M., et al. (2019). Dynamic control of enhancer activity drives stage-specific gene expression during flower morphogenesis. Nat. Commun. 10:1705. doi: 10.1038/s41467-019-09513-2

Yang, N., Xu, X. -W., Wang, R. -R., Peng, W. -L., Cai, L., Song, J. -M., et al. (2017). Contributions of Zea mays subspecies mexicana haplotypes to modern maize. Nat. Commun. 8:1874. doi: 10.1038/s41467-017-02063-5

Yip, K. Y., Cheng, C., and Gerstein, M. (2013). Machine learning and genome annotation: a match meant to be? Genome Biol. 14:205. doi: 10.1186/ gb-2013-14-5-205

Zekic, F., Weselowski, B., and Yuan, Z. -C. (2017). Complete genome sequence of Burkholderia cenocepacia CR318, a phosphate-solubilizing bacterium isolated from corn root. Genome Announc. 5, e00490-e00417. doi: 10.1128/ genomeA.00490-17

Zhang, L., Cai, X., Wu, J., Liu, M., Grob, S., Cheng, F., et al. (2018). Improved Brassica rapa reference genome by single-molecule sequencing and chromosome conformation capture technologies. Hortic. Res. 5:50. doi: 10.1038/ s41438-018-0071-9

Zhang, Y. -C., Liao, J. -Y., Li, Z. -Y., Yu, Y., Zhang, J. -P., Li, Q. -F., et al. (2014). Genome-wide screening and functional analysis identify a large number of long noncoding RNAs involved in the sexual reproduction of rice. Genome Biol. 15:512. doi: 10.1186/s13059-014-0512-1

Zhang, Y., Malzahn, A. A., Sretenovic, S., and Qi, Y. (2019b). The emerging and uncultivated potential of CRISPR technology in plant science. Nat. Plants 5, 778-794. doi: 10.1038/s41477-019-0461-5

Zhang, W., Zhang, T., Wu, Y., and Jiang, J. (2012). Genome-wide identification of regulatory DNA elements and protein-binding footprints using signatures of open chromatin in Arabidopsis. Plant Cell 24, 2719-2731. doi: 10.1105/ tpc.112.098061

Zhang, B., Zhu, W., Diao, S., Wu, X., Lu, J., Ding, C., et al. (2019a). The poplar pangenome provides insights into the evolutionary history of the genus. Commun. Biol. 2:215. doi: 10.1038/s42003-019-0474-7
Zhao, Q., Feng, Q., Lu, H., Li, Y., Wang, A., Tian, Q., et al. (2018b). Pangenome analysis highlights the extent of genomic variation in cultivated and wild rice. Nat. Genet. 50, 278-284. doi: 10.1038/s41588-018-0041-z

Zhao, H., Zhang, W., Chen, L., Wang, L., Marand, A. P., Wu, Y., et al. (2018a). Proliferation of regulatory DNA elements derived from transposable elements in the maize genome. Plant Physiol. 176, 2789-2803. doi: 10.1104/pp.17.01467

Zhou, Z., Jiang, Y., Wang, Z., Gou, Z., Lyu, J., Li, W., et al. (2015b). Resequencing 302 wild and cultivated accessions identifies genes related to domestication and improvement in soybean. Nat. Biotechnol. 33, 408-414. doi: 10.1038/ nbt.3096

Zhou, P., Silverstein, K. A. T., Ramaraj, T., Guhlin, J., Denny, R., Liu, J., et al. (2017). Exploring structural variation and gene family architecture with De Novo assemblies of 15 Medicago genomes. BMC Genomics 18:261. doi: 10.1186/s12864-017-3654-1

Zhou, J., and Troyanskaya, O. G. (2015). Predicting effects of noncoding variants with deep learning-based sequence model. Nat. Methods 12, 931-934. doi: 10.1038/nmeth.3547

Zhou, L., Wang, S. -B., Jian, J., Geng, Q. -C., Wen, J., Song, Q., et al. (2015a), Identification of domestication-related loci associated with flowering time and seed size in soybean with the RAD-seq genotyping method. Sci. Rep. 5:9350. doi: 10.1038/srep09350

Zhu, B., Zhang, W., Zhang, T., Liu, B., and Jiang, J. (2015). Genome-wide prediction and validation of intergenic enhancers in Arabidopsis using open chromatin signatures. Plant Cell 27, 2415-2426. doi: 10.1105/tpc.15.00537

Zsögön, A., Čermák, T., Naves, E. R., Notini, M. M., Edel, K. H., Weinl, S., et al. (2018). De novo domestication of wild tomato using genome editing. Nat. Biotechnol. 36, 1211-1216. doi: 10.1038/nbt.4272

Conflict of Interest: The authors declare that the research was conducted in the absence of any commercial or financial relationships that could be construed as a potential conflict of interest.

Copyright () 2020 Pourkheirandish, Golicz, Bhalla and Singh. This is an open-access article distributed under the terms of the Creative Commons Attribution License (CC BY). The use, distribution or reproduction in other forums is permitted, provided the original author(s) and the copyright owner(s) are credited and that the original publication in this journal is cited, in accordance with accepted academic practice. No use, distribution or reproduction is permitted which does not comply with these terms. 